\title{
POPULATION DYNAMICS OF THE MAIN PELAGIC SPECIES EXPLOITED IN THE JAVA SEA: STOCK EVALUATION
}

\author{
Bambang Sadhotomo")
}

\begin{abstract}
This study was based on length composition data collected from purse seine fleets operating in the Java Sea, and aimed to elaborate the state of the stock of the main species. Two approaches, i.e. cohort analysis and dynamic pool model were employed in order to simulate the effect of fishing mortality being generated by mini purse seine fishery on the yield, as well as to describe the population structure by size. The impact of exploitation of the young fishes by small scale fishery on the the total yield was considerably not important. However, the accuracy of the analysis seemed to be hampered by pseudo estimates of mortality parameters, due to the condition that the structure of data input were strongly influenced by migration phenomenon and fishing strategy.
\end{abstract}

KEYWORDS: $\quad$ small pelagic, yield per recruits, cohort, stock, mortality, Java Sea

\section{INTRODUCTION}

In term of population dynamics, i.e. changes with time, there are several factors governing variation of the population size, namely number of recruits, mortality, and somatic growth of individuals. However, the process of population changes is more complicated. We believe that these changes in the system in the nature of the Java Sea can not be simply described as compartement diagram or equation showing equilibrium of influx, growth, removal, and natural death. In the context of fisheries problems, separate analysis of the part of the dynamic system would be still valuable in explaining possible influence of the ecological dimension on the characteristics of population structure.

Fish stocks are commonly estimated by performing one or more methods of the following three categories of approaches. The first one is direct method, that usually apply acoustics by converting roughly the biomass from acoustic deviation data. The second approach is the global or surplus production model. All of the family of this model at least need catch and effort data with steady state equilibrium assumption underlying the model. The last approach is age based model. It is due to Beverton \& Holt (1957) who modelled the populations change with time varies in deterministic or mathematical equations. Another age based method is virtual population analysis that is a procedure for determining number of individuals fish based on catch at age data.

Since the origin version of the last approach requires that the catch is classified into ages, Jones $(1974 ; 1981)$; Pope (1984) pointed out that length composition data can be used in the same fashion. In this case, the growth parameter estimates are absolutely required for converting length into age. With assuming Von Bertalanffy growth model, we perform the yield per recruit model of Beverton \& Holt (1957) and Jones' length cohort analysis (Jones, 1981) for 2 species of Decapterus, Amblygaster sirm, and Sardinella gibbosa. In this study, length based models are applied with particular caution due to incomplete data required for modelization and mortality estimation.

In fact, the accuracy of this approaches may be hampered by insufficient information from other fisheries exploiting the Java Sea'stock, while our main data were collected from the big and medium purse seine fishery landing in the main fishery harbor in the north coast of Java. This constraint relates to the migratory behavior of the pelagic fishes, as well as unreliability of the statistical data in the regions outside Central Java province.

The pelagic fisheries in the Java Sea consist of different type of fishing gear having different selectivity by species and size. However, the large and medium purse seine contribute more than $60 \%$ of Decapterus spp and A. sirm, and around $30 \%$ of $S$. gibbosa to the total landing of the same taxonomic group in the Java Sea area (included south of Kalimantan). For this reason, we assume that the catch data are coming from the same population and no other fishery (except of the Javanese fishery) exploit the same stock. But precaution should be taken for possible bias generated by inaccurate official statistical data.

Many fishing gears are used to catch the same species beyond the fishing areas of the Javanese

Research Center for Capture Fisheries, Muara Baru-Jakarta 
purse seine, but only three type of gears probably have significant contribution to the total removal. The first one is the mini purse seine that widely adopted by fishermen in most of the region surrounding the Java Sea, i.e. all part of Malacca Strait, southern part of Sumatra region (around Bangka and Belitung Island), along north coast of Java, some subarea in the Lesser Sunda archipelago, and the south and south east of Sulawesi. The second one is another type of seining gear, namely as payang. The total catch of Rastrelliger kanagurta landed by payang boats in the southeast area of Kalimantan was enormous, reported to be around 20,000 ton per year (DGF, $1994 ; 1995)$. Along the north coast of Java this gear catches sardine and anchovy as complementary one, but around Bawean and Kangean Island payang boats also catch Decapterus as reported in the statistical data of Brondong fishing port (Luong, 1997).

\section{MATERIAL AND METHODS}

\section{Length Cohort Cohort Analysis}

\section{Derivation}

yearly basis catch at given class of age may be used to estimate population parameter, biomass, etc. This method provides an estimate of original number of individual of a year class being based on number of removal from that year class throughout its life. Analysis associates to this approach is known as virtual population analysis, Gulland's method or Murphy's method.

Pope (1972) developed a simple approximation to virtual population technique by providing the basic formulae for this analysis. The basic procedure for this method then was called as cohort analysis.

Jones length cohort analysis (Jones, 1981) is based on the extension of Pope's cohort analysis formula to time variable interval. The method uses common deterministic assumption that within any one age group the decline in number with time variable follow an exponential decay function, which can be expressed as:

$$
N_{t+1}=N_{t} \cdot e^{-Z}
$$

where:

$$
\begin{aligned}
\mathrm{N}_{\mathrm{t}+1}= & \text { number in the sea at age } \mathrm{t}+1 \\
\mathrm{Z}= & \text { instantaneous total mortality } \\
& \text { exponential basis) }
\end{aligned}
$$

In cohort analysis the exponential curve within any age group is replaced by a step function which is based on the following assumptions:

1. The whole catch for that age group is taken at middle of age interval.

2. Natural loss is constant through all age (instantaneous natural mortality, $\mathrm{M}$ is constant)

Detail of the derivation was presented in Pope (1972); Jones (1981).

In this study, we apply the basic model of Jones length cohort analysis. Fishing mortality and cohort size (biomass of the survivors) are estimated from the catch at length data alone without any auxiliary data (such as fishing effort). For the length cohort analysis applied in this study, we use catch in numbers from beginning of recruitment to largest group following the tendency of modal progression. The periods of data set are defined as the same period of those used for growth estimation.

In fact, this method needs the data to perform to a steady state condition. It is impossible to know this condition without elucidating the historical data of catch and effort. In practice, it can be approximated by averaging the catch at length data for couple of years (Pope, 1980). For this reason we use the catch at length data of $D$. russellii and $D$. macrosoma from three years periods (i.e. 1993 to 1995). While for S. gibbosa we apply to one year period (1994 or 1995) because of the lack of measurement data from other fishery, but assumption of steady state condition can be taken as this species is more coastal and considerably undergo heavy fishing pressure.

\section{Dynamic Pooled Model}

Dynamic pooled model or yield per recruit model was firstly introdued by Beverton \& Holt (1957), and widely used for analysing age composition data. Feature of this model are that life history is treated into 2 parts, one part is the pre recruitment age, and another parts is from recruitment onward. The core of this method is to modelise the change of population from recruitment to maximum age attaining, by sub dividing into age groups. The original model was completely deterministic, and the derivation was based on differential equation. The theory and mathematical derivation have been exhaustively presented in Beverton \& Holt (1957). Probably due to the problem of computation (at that period) Beverton \& Holt (1957) reparameterized the This work is a part of the more comprehensive study carried out by the Java Sea Pelagic Assessment Project during the period of
$1991-1995$ 
original model that enable to compute the yield easier. Assuming that an isometric von Bertalanffy growth equation (i.e. weight $\sim$ cubic length), then yield can be expressed as following discrete equation:

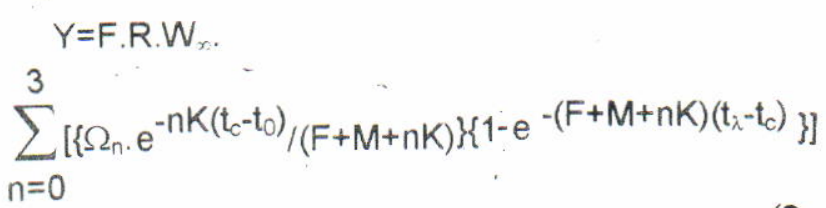

where:

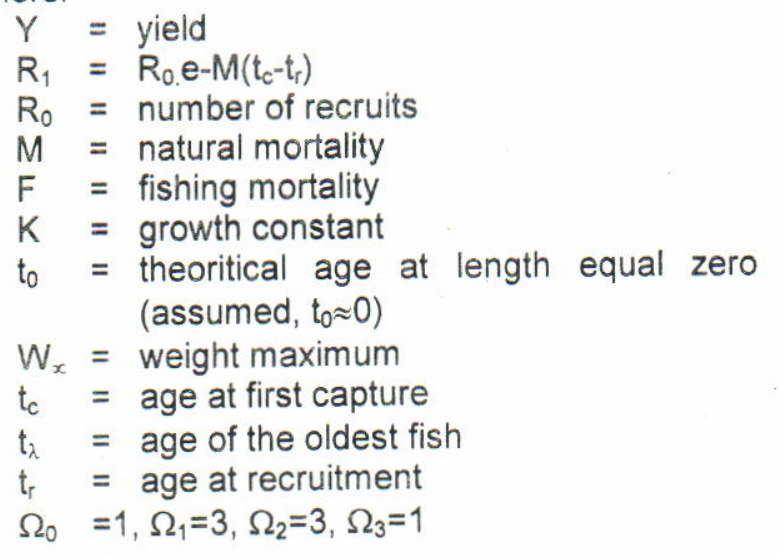

For two fishing gear or 2 type of fisheries exploit the same stock at different age at first capture, Marcille (1978) proposed a modification, within the principle of the basic equation. However, this extension can be applied for any range of age captured by the fisheries (Figure 1 (b)). In the case of overlapping age at first capture (also valid for length at first capture), yield can be expressed as:

$$
Y=Y_{1.0}+Y_{1.1}+Y_{2.0}+Y_{2.1}
$$

where subscribs 1.0,1.1 and 2.0, 2.1 corresponding to the partial yield for particular range of age of first and second fisheries (i.e. due to $F 1$ and $F 2$ ), respectively:

$$
\begin{aligned}
& \mathbf{Y}_{1,0}=\mathbf{F}_{1} \cdot \mathbf{R}_{1}, \mathbf{W}_{\infty} . \\
& \sum_{n=0}^{3}\left[\left\{\Omega_{n} e^{-n K\left(t_{\left.c_{1}-t_{1}\right)}\right)} /\left(F_{1}+M+n K\right)\right\}\left\{1-e^{-\left(F_{1}+M+n K\right)\left(t_{c}-t_{1}\right)}\right\}\right] \\
& \mathbf{Y}_{1.1}=\mathbf{F}_{1} \cdot \mathbf{R}_{2}, \mathbf{W}_{\infty} . \\
& \sum_{n=0}^{3}\left[\left\{\Omega_{n} e^{-n K\left(t_{2}-t_{1}\right)} /\left(F_{1}+M+n K\right)\right\}\left\{1-e^{-\left(F_{1}+M-n K\right)\left(t_{0}-t_{c 2}\right)}\right\}\right] \\
& \mathrm{Y}_{2.0}=\mathrm{F}_{2} \cdot \mathbf{R}_{\mathbf{2}} \mathrm{W}_{\infty} \\
& \sum_{n=0}^{3}\left[\left\{\Omega_{n} e^{-n K\left(t_{2}-t_{11}\right)} /\left(F_{2}+M+n K\right)\right\}\left\{1-e^{-\left(F_{2}+M+n K\right)\left(t_{0}-t_{c_{1}}\right)}\right\}\right] \\
& Y_{2.1}=F_{2} \cdot R_{3} . W_{\infty} \text {. } \\
& \sum_{n=0}^{3}\left[\left\{\Omega_{n} e^{-n K\left(t_{\omega^{1}}-t_{0}\right)} /\left(F_{2}+M+n K\right)\right\}\left\{1-e^{-\left(F_{2}+M+n K\right)\left(t_{\sigma^{2}-t_{0}}\right)}\right\}\right]
\end{aligned}
$$

where, $R_{1}=R_{0} e-M\left(t_{c 1} \cdot i_{r}\right)$ is numbers of recruits, $R_{2}=R_{1} e-\left(M+F_{1}\right)\left(t_{\lambda 1}-t_{c 1}\right), R_{3}=R_{2} e-M\left(t_{c 2}-t_{\lambda 1}\right)$

In this study, we calculate yield per recruit (i.e. $Y / R$ ) rather than yield, for the. second model that 2 fisheries exploit the same stock in overlapping age group. We define that the second fishery is the large purse seine and the first one could be small scale fishery utilizing other type of fishing gears.

a. Single gear fishery

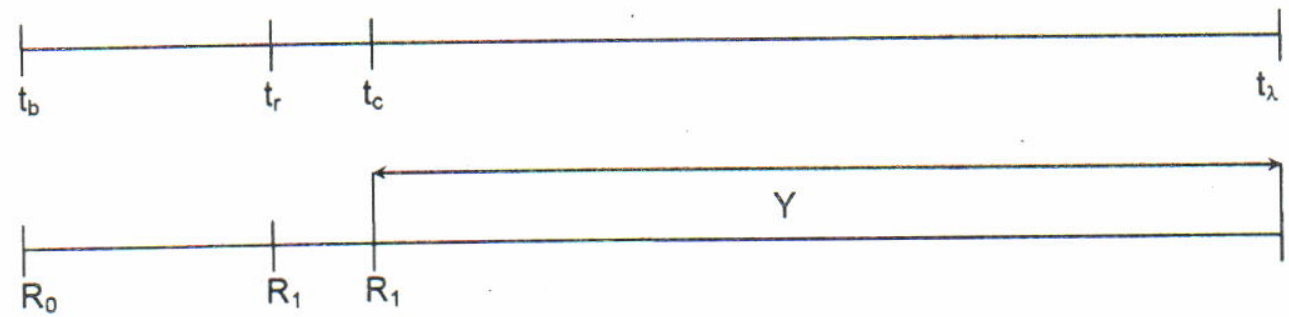

b. Dual gear fishery with overlapping range of age enter the fishery

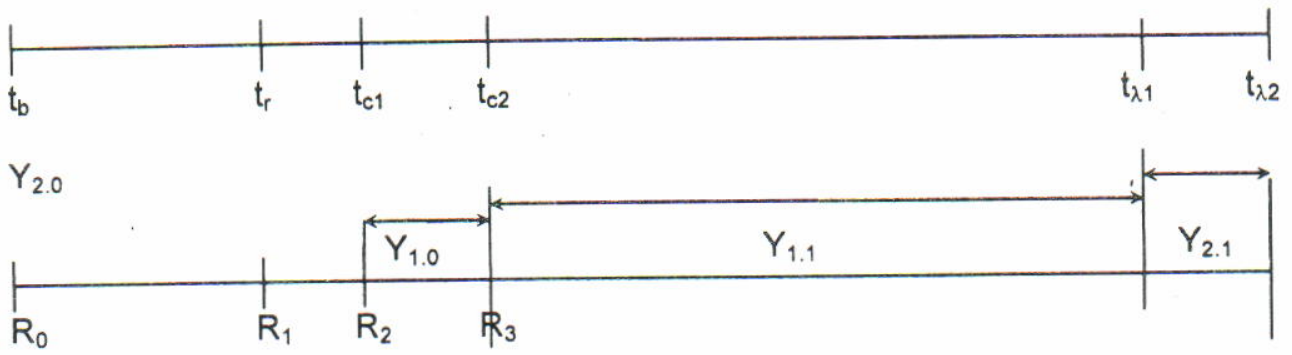

Figure 1. Diagrams showing the range of age exploited by two types of fisheries (Marcille, 1978). 
The first step is to compute yield per recruit is for $F_{2}$ and $L_{c 2}$ vary at arbritary value of $F_{1}$ and presenting the result in isopleth diagrams.

The second step is done in the similar manner, but with $L_{c 2}$ are fixed at given values. It is mainly aimed to determine the optimum fishing mortality (as so called as F optimum and denoted as $F_{\text {opt }}$ ). Optimum value of fishing mortality of second fishery can be calculated in 2 ways:

a. $F_{\text {opt }}$ is equal to the value of $F$ giving maximum yield or yield per recruit, i.e. $F_{o p t}=F_{\max }$.

b. In case that $M$ is relatively large, the $F_{\text {opt }}$ may be very large and tends to be unreasonable or may not exist. The concept of $F_{0.1}$ as another criteria to define the optimum value of $F$ can be adopted for this case. $F_{\text {opt }}$ is defined as fishing mortality rate corresponding to a rate of increase in yield with $\mathrm{F}$ being 0.10 of the initial rate of increase at the start of fishing (Gulland \&

\section{Structure of Catch and Length at First Capture}

Boerema, 1973). This value is denoted as $F_{0.1}$ that can be mathematically derived as the first partial derivate of yield function (with subject to $\mathrm{F})$ at conditional restriction $\mathrm{F}=\mathrm{F}_{0.1}$. It can be expressed as (Gulland \& Boerema, 1973):

$$
\left.\frac{\delta Y}{\delta F}\right|_{F=F_{0.1}}=\left.0.1\left(\frac{\delta Y}{\delta F}\right)\right|_{F=0}
$$

In practice, it can be illustrated graphically by taking tangent line at the initial rate of increase in yield (line a) and measuring the slope to the absisca (as angle of $\alpha$ ). Then taking a tangent line (line c) which is parallel to the line $b$ having slope of 0.1 . This is a tangential to the yield curve at the point having coordinate $\left(F_{0.1} ; Y_{0.1}\right)$, where $Y_{0.1}$ is yield per recruit at $F_{0.1}$ Figure 2).

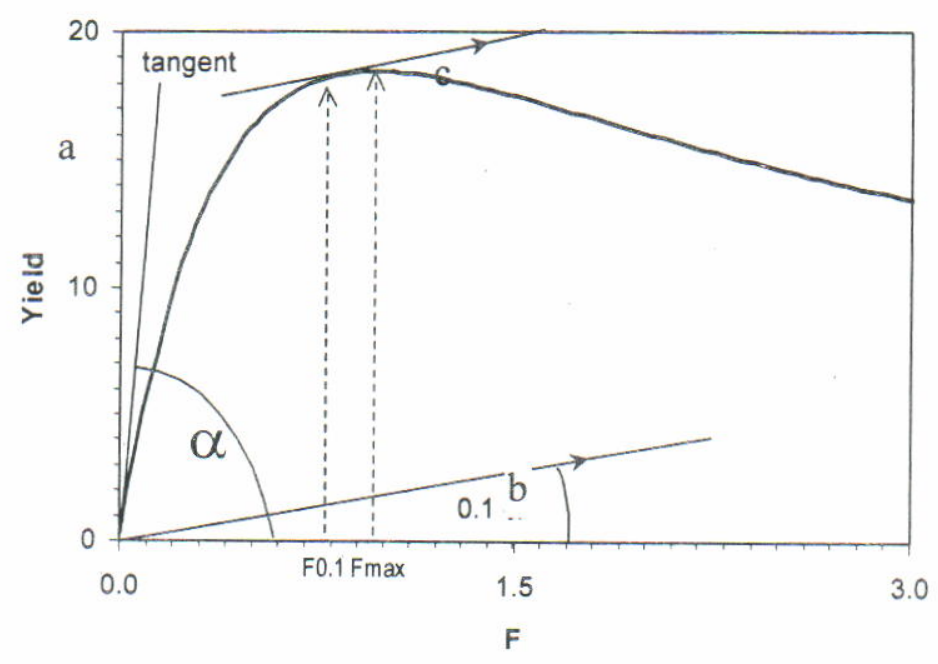

Figure 2. Showing hyphothetical diagram of yield function and graphical estimation of $F_{0.1}$.

\section{RESULTS AND DISCUSSION}

\section{Population Parameters}

Two important parameters related to the population are estimated using length composition data, i.e. the length at first capture and mortality. A brief discussion on repartition of the catch by type of fishery is given, in order to describe possible bias of our estimates.
Length at which $50 \%$ of fish captured can be reflected by length at probability $50 \%$ derived from cumulative frequency distribution. We estimate the length at first capture by category of fishing boats of the purse seine, as they tend to catch fish in different size (Sadhotomo \& Potier, 1995). Quarterly based estimations are performed as well as the last 2 years periods of observations (1993 or 1994 and 1994 or 1995). The estimates are discriminated according to boat size category: large, medium and mini purse seine. General

\footnotetext{
This work is a part of the more comprehensive study carried out by the Java Sea Pelagic Assessment Project during the period
of $1994-1995$
} 
explanation on the catch structure is also reviewed in relation to the operation of fishing fleets.

\section{Length at First Capture of Large and Medium Seine}

Rough estimates can be performed by interpolating some points from cumulative frequency (Figure 3 and Table 1). Immediate conclusion can be drawn concerning with the different vulnerability of the species to the size category of fishing boat (also for the fishing gear). Generally speaking, large seiners tend to catch slightly bigger size of fishes (Figure 4,5), even though those type of boat use the same fishing methods. Similar tendency has been presented in the previous studies using length data of 1991 to 1992 (Sadhotomo \& Potier, 1995).

In this part we focus our analysis on the three main species, e.g. Decapterus russellii, $D$. macrosoma, and Sardinella gibbosa. We noticed that the two type of boats may catch the same cohort with some exception during certain periods, i.e. for $D$. russellii and $R$. kanagurta, during quarters January to March 1995, and October to December 1995, respectively. In the peak of fishing season (August to November) the differences seem to decrease, particularly for migrant species. However, different fishing ground can be regarded as source of this variability that the medium seiner tend to prospect the fishing ground near main island, i.e. North Coast of Java waters, Karimunjawa and Bawean Bank that usually inhabited by younger fish. Characteristic of the three fishing grounds, where medium seiner usually operated, can be considered as more coastal than other zones. As shown by average fish length sampled from medium seiner, a general phenomenon of the occurrence of smaller fish in the near coastal area may be evident.

Comparison of the fish length structure of caught by the 2 categories of gears (e.g. during May or June 1993 to April or May1994) indicates significant difference of fish size of the migrant species, such as Decapterus macrosoma and $R$. kanagurta. However, it should not be interpreted as possibly impact of difference size of the mesh of net, as the selectivity is mostly influenced by the operation. Two sources of influences may be inferred from the change characteristic of the medium seiner after 1994.

Before that year, most of the medium seiner used to be equipped by lower intensity of light for aggregating the fish i.e. mercury bulp lamps. After this period, more proportion of new boats classified as this category utilize the same lighting apparatus and fishing strategy as those of the large seine. The better autonomy and more powerful engine seem to enable the medium purse seine to operate in the same strategy and to use the same lighting (i.e. the use of metal halide lamps replacing the mercury bulps) as the larger category. Reason why, in the successive year, the length at first capture derived from the medium seine catch does not indicate any significant difference. But, in order to avoid any bias may be generated by this fact, we treat the data separately, especially in raising up the length frequency.

\section{Mini Purse Seine}

Mini purse seine fleets also exploit the pelagic species along coastal area of Java Island, from Kangean Island until Sunda Strait. The catch composition may vary with the location of fishing zones, as the fleets tend to move systematically following aggregations of the most profitable aggregation of fish. In the fishing zone around Bawean and Karimunjawa Island the monthly fluctuation of catch shows a similar trend with ones of the medium seiner.

It may be demonstrated by catch composition samples from Sarang fishing port (its latitude is between Karimunjawa and Bawean Islands). In this subarea scads seem to be the main target during the south east monsoon, while in other subarea the mini purse seine tend to prospect other species (Auxis spp., Thunnus tonggol, sardine, and black pomfret).

High contribution of Decapterus to the total landing during peak of fishing season (August to November) is obviously observed, on the contrary, the sardine catch is more important during the opposite season (Figure 6). In Pekalongan harbor where the mini purse seine operating in north coast of central Java unload their catch, the Decapterus russellii category has never been recorded in the auction data base, although low percentage of this category occasionally exist in the catch. Nevertheless, the length of this species caught by mini purse seine appears to be similar with that of medium one, in their pattern and size (unfortunately, only 2 samples of length measurement taken in this fishing port consist of Decapterus russellii).

We used official statistics published annually (DGF, 1996) for estimating the total catch of $S$. gibbosa coming from the Java Sea stock, due to invariability of better statistical data. The length composition of the sardine species are based on 
45 samples measured in Pekalongan during the periods of April to June 1995 and September to November 1994 (Figure 7). In general, the average fish length of mini purse seine samples is about 1 $\mathrm{cm}$ shorter than those of big and medium seines ones, and on other hand the monthly catch of sardine of the big and medium seines tend to exhibit a similar fluctuation. It means that the 2 types of gears may exploit the same cohorts and there is no relation to slight different length at first capture of the two purse seine category. Pooled catch at length data of the all type of purse seiner category can be used as data input for further analysis (Table 2).

Table 1. Length at probability of $50 \%$ of the main pelagic species by purse seiner category

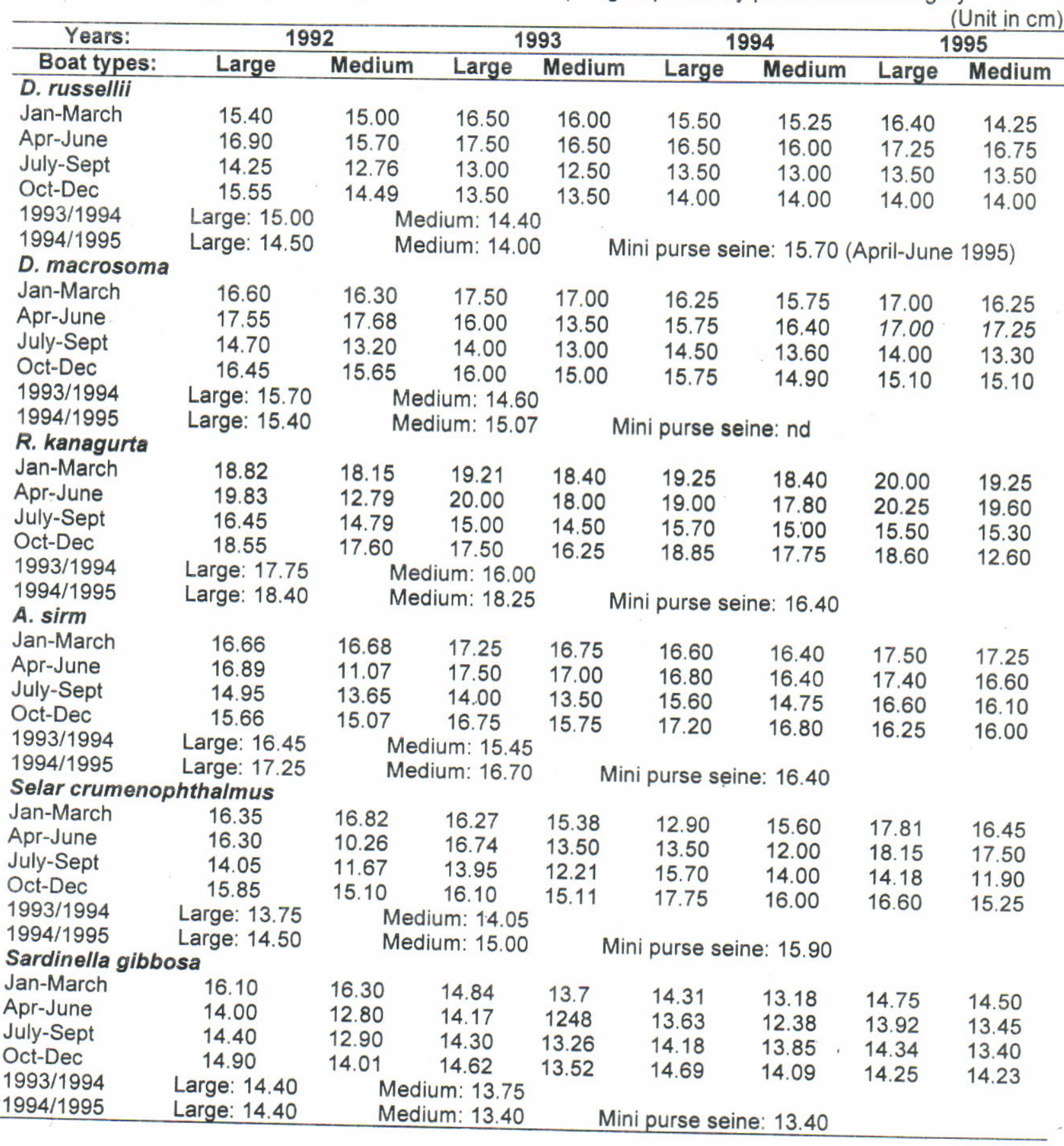



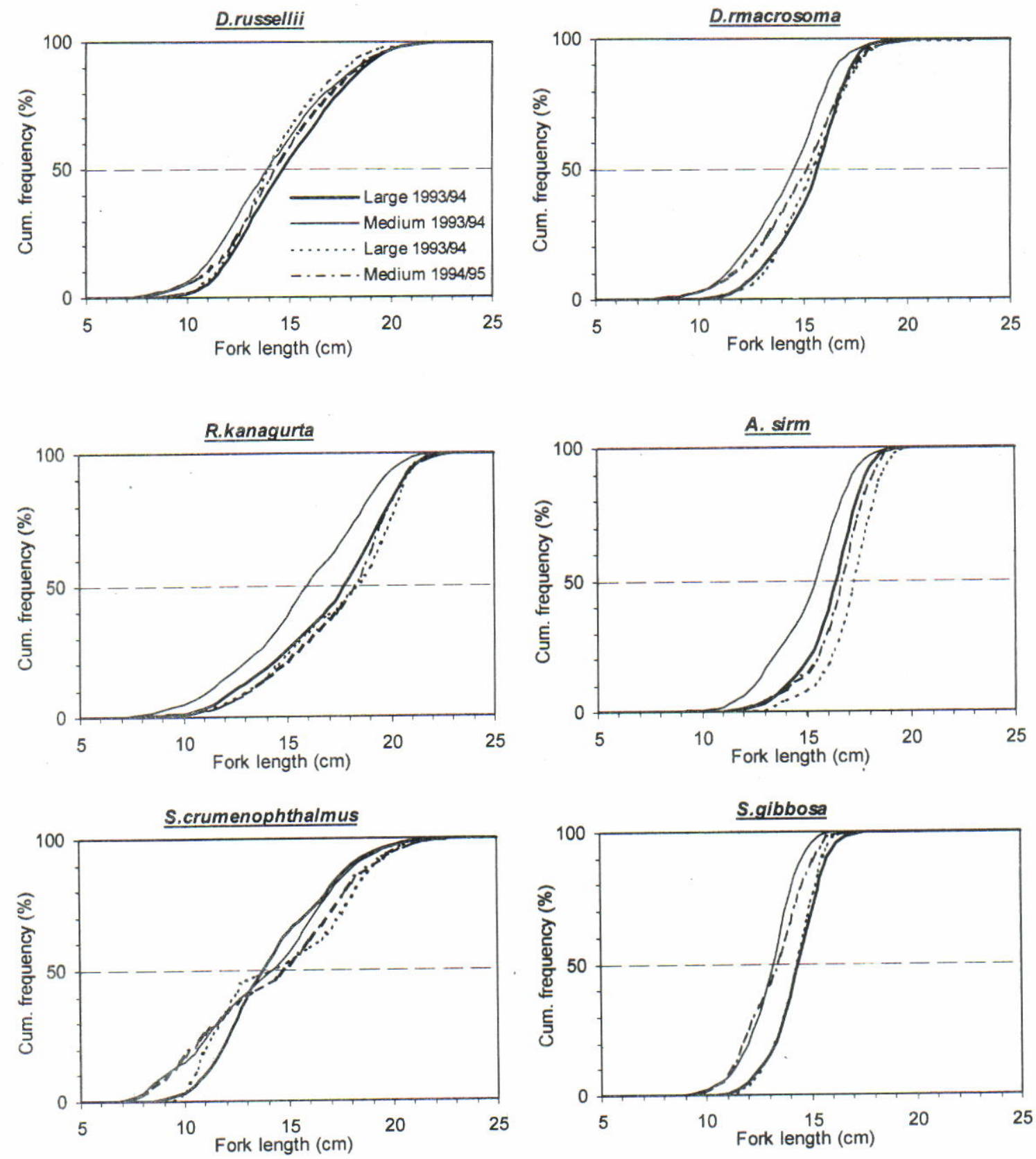

Figure 3. Cumulative length frequency of the main species by type of fishery in the Java Sea area.

In this case, we perform two ways of data pooling for Decapterus. In the first way, the data of the years of 1993 or 1994 and 1994 or 1995 are treated separately (not presented in the above table), and the second one, we use average of the two periods in order to have an input for more equilibrium condition. For Amblygaster sirm, pooled data of 1991 to 1995 are used with assuming that no another fishery exploiting this population. While for Sardinella gibbosa, only the data of the period 1993 or 1994 are used with taking into consideration that this species is heavily fished by coastal fishery. Raising up the samples of this species is done by multiplying the length frequency data with two factors corresponding to the origin of the samples. The first factor is for the length composition measured from the large and medium purse seiner that calculated as ratio of total catch of this semi industrial fishery divided by calculated weight of samples.

The second one is for raising up the length frequency measured from the mini purse seiner landed in Pekalongan during the period 1994 or 1995 which is defined as ratio of total catch of sardine in the Java Sea as reported officially minus 

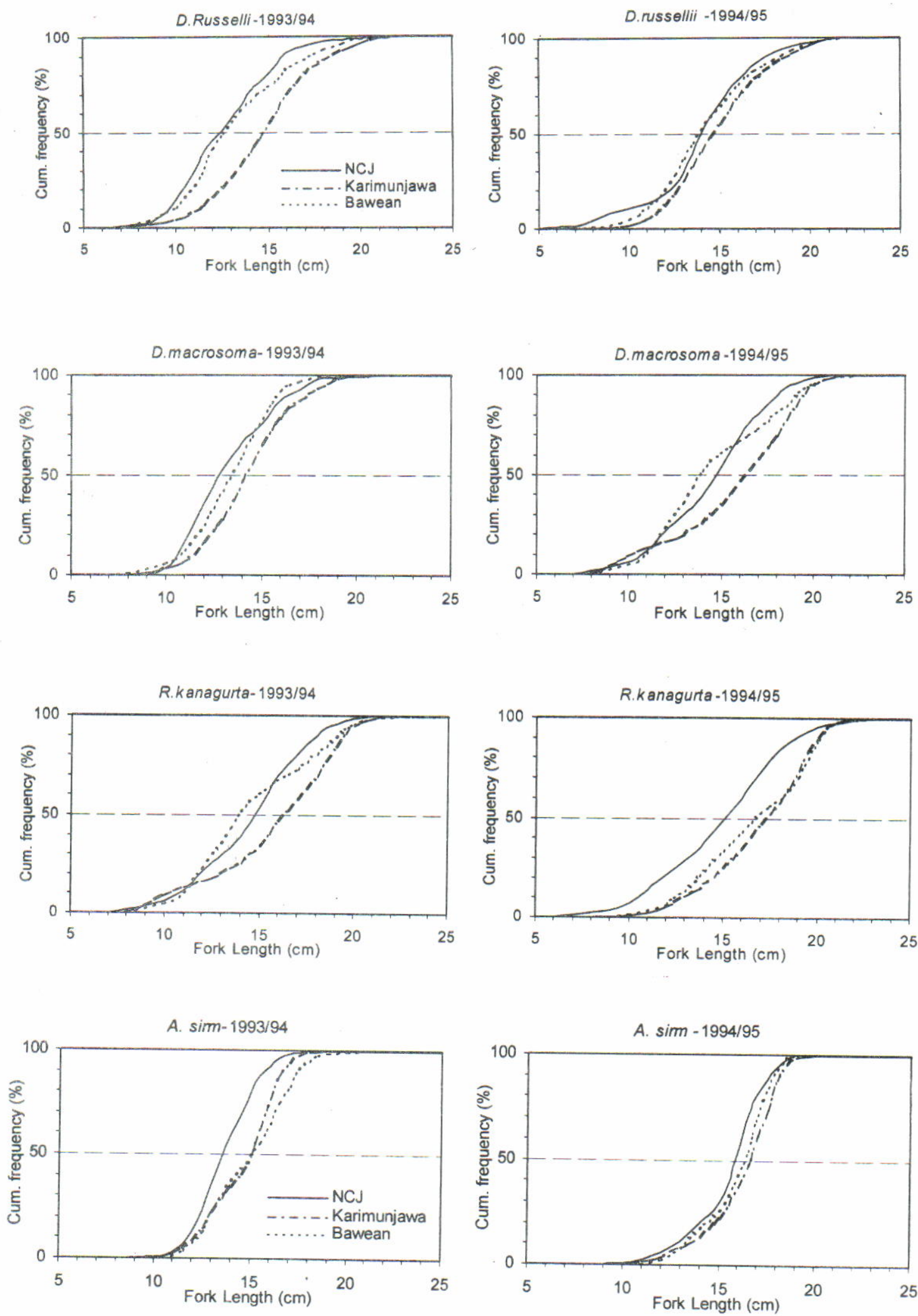

Figure 4. Cumulative frequency of length by sub area of the main species caught by big purse seiner. 

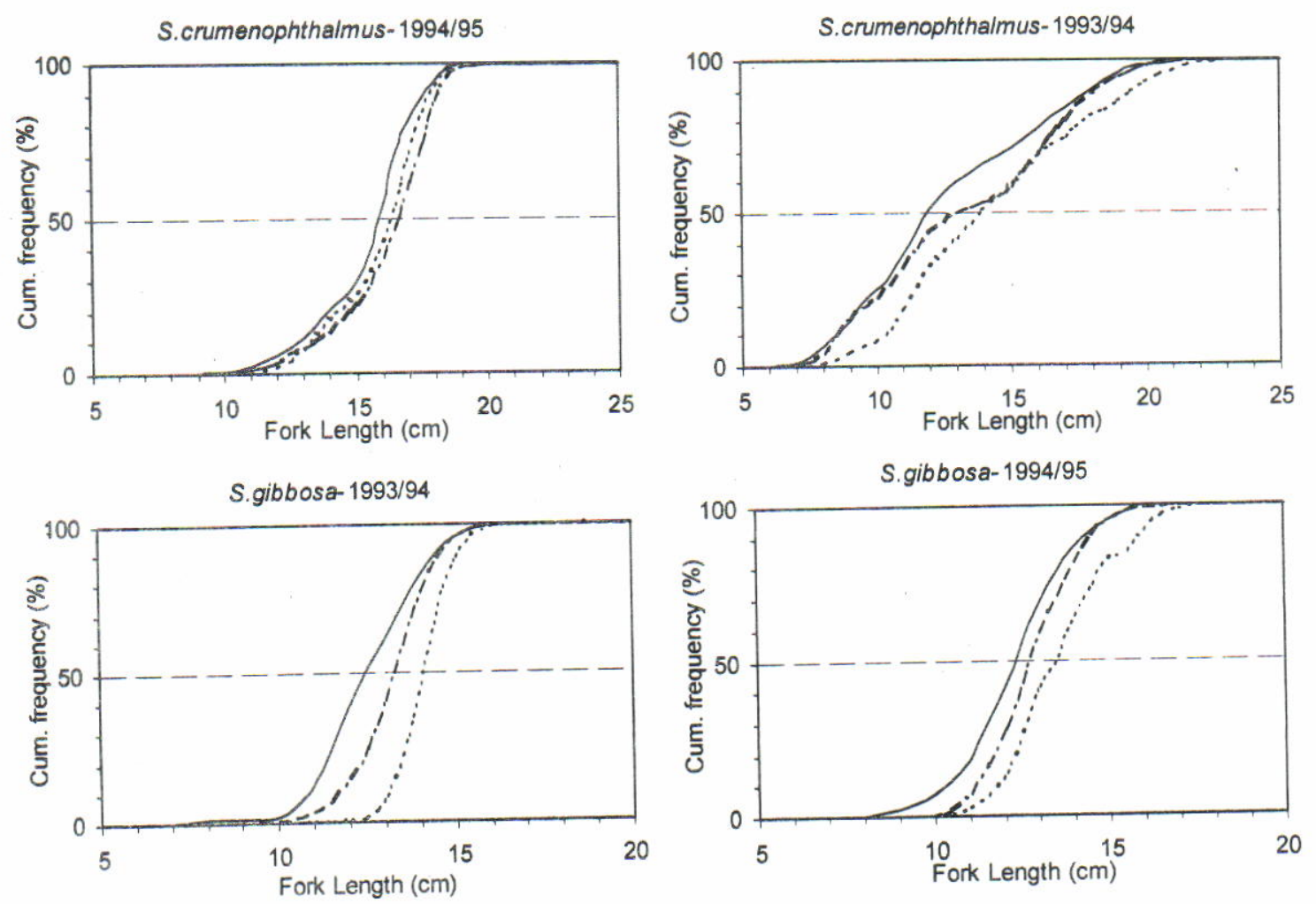

Figure 5. Cumulative length frequency of the main species caught by medium purse seine in the near coastal fishing zones.

Decapterus spp. m melar 目Selar crumenophthalmus 田Sardinellagibbosa $\square O T H E R S$

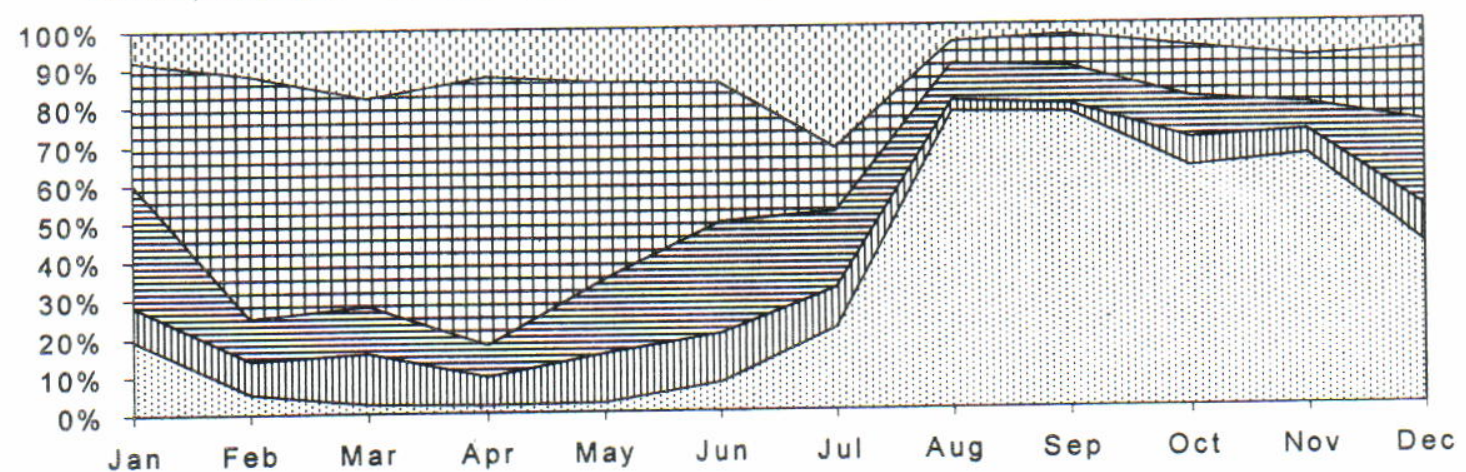

Figure 6. Monthly catch composition of mini purse seine landed in Sarang. Source: auction sample data of Sarang fishing port

the total catch of large and medium seiner, divided by weight of samples. In this case, we consider that the estimated catch of the large and medium seine fishery is more reliable.

\section{Mortality}

\section{Total Mortality}

Total instantaneous mortality (denoted as Z) is estimated by means of catch curve. It is derived from the exponential decay equation of population change. This method commonly employs age composition data of the catch with assuming that the catches represent or proportional to the abundance at sea (Beverton \& Holt; Ricker, 1975). Since the method requires catoh at age data input, and the fact that aging data are not available, the catch at length data coming from non selective fishing gears can be used in similar manner as age composition ones to derive a catch curve (Gulland, 1983). Converting length into age using Von Bertalanffy growth formula with previously estimated parameters (Sadhotomo, 1998), then Z 
Table 2. Estimates of average catch at length of four pelagic species

\begin{tabular}{|c|c|c|c|c|c|c|c|c|}
\hline \multirow{3}{*}{$\begin{array}{c}\text { Years: } \\
\text { Mid } \\
\text { length } \\
(\mathrm{cm})\end{array}$} & \multirow{2}{*}{\multicolumn{2}{|c|}{$\begin{array}{l}\text { D. russellii } \\
1992-1995\end{array}$}} & \multirow{2}{*}{\multicolumn{2}{|c|}{$\begin{array}{c}\text { D.macrosoma } \\
1992-1995\end{array}$}} & \multirow{2}{*}{\multicolumn{2}{|c|}{$\begin{array}{l}\text { S. gibbosa } \\
1993 / 1995\end{array}$}} & \multirow{2}{*}{\multicolumn{2}{|c|}{$\frac{\text { A. sirm }}{1991-1995}$}} \\
\hline & & & & & & & & \\
\hline & $\begin{array}{c}\text { Catch in } \\
\text { weight } \\
\text { (mt) }\end{array}$ & $\begin{array}{c}\text { Catch in } \\
\text { number } \\
\left(10^{4}\right)\end{array}$ & $\begin{array}{c}\text { Catch in } \\
\text { weight } \\
\text { (mt) }\end{array}$ & $\begin{array}{c}\text { Catch in } \\
\text { number } \\
\left(10^{4}\right)\end{array}$ & $\begin{array}{c}\text { Catch in } \\
\text { weight } \\
\text { (mt) }\end{array}$ & $\begin{array}{c}\text { Catch in } \\
\text { number } \\
\left(10^{4}\right)\end{array}$ & $\begin{array}{c}\text { Catch in } \\
\text { weight } \\
\text { (mt) }\end{array}$ & $\begin{array}{c}\text { Catch in } \\
\text { number } \\
\left(10^{4}\right)\end{array}$ \\
\hline 5.5 & 0 & 459 & 0 & 1,132 & 7 & 17,691 & & \\
\hline 6.5 & 1 & 3,947 & 2 & 8,381 & 19 & 31,188 & 0 & 221 \\
\hline 7.5 & 6 & 20,321 & 10 & 29,330 & 181 & 207,908 & 1 & 2,060 \\
\hline 8.5 & 26 & 55,370 & 47 & 86,616 & 1,033 & 858,489 & 4 & 5,511 \\
\hline 9.5 & 96 & 134,465 & 169 & 211,642 & 4,290 & $2,671,128$ & 8 & 8,501 \\
\hline 10.5 & 326 & 319,538 & 557 & 495,655 & 9,575 & $4,583,143$ & 23 & 16,527 \\
\hline 11.5 & 971 & 690,380 & 1,459 & 950,017 & 8,619 & $3,241,626$ & 68 & 36,370 \\
\hline 12.5 & 2,397 & $1,270,931$ & 3,311 & $1,618,330$ & 9,654 & $2,906,416$ & 159 & 64,894 \\
\hline 13.5 & 4,583 & $1,856,845$ & 6,832 & $2,563,288$ & 5,784 & $1,416,015$ & 327 & 103,783 \\
\hline 14.5 & 7,015 & $2,217,271$ & 12,307 & $3,611,643$ & 3,832 & 773,554 & 674 & 169,182 \\
\hline 15.5 & 8,703 & $2,184,279$ & 19,176 & $4,474,116$ & 1,403 & 236,285 & 1,750 & 352,879 \\
\hline 16.5 & 9,082 & $1,837,992$ & 24,526 & $4,615,383$ & 486 & 69,067 & 3,587 & 589,088 \\
\hline 17.5 & 8,361 & $1,382,995$ & 24,113 & $3,706,247$ & & & 4,760 & 644,630 \\
\hline 18.5 & 7,182 & 982,449 & 17,477 & $2,218,872$ & & & 3,354 & 378,635 \\
\hline 19.5 & 6,299 & 720,191 & 8,209 & 869,591 & & & 1,181 & 112,180 \\
\hline 20.5 & 5,289 & 510,173 & 2,553 & 227,660 & & & 282 & 22,728 \\
\hline 21.5 & 3,926 & 322,217 & 726 & 54,979 & & & 45 & 3,088 \\
\hline 22.5 & 3,686 & 240,315 & 734 & 47,544 & & & 3 & 189 \\
\hline Total & 67,948 & & 61,104 & & 44,883 & & 16,227 & \\
\hline
\end{tabular}

can be derived by plotting or regressing the natural logarithm of relative abundance of consecutive length classes against relative age (calculated age with $t_{0}$ to be assumed equal to zero).

In this estimation, an attention should be taken on the assumption underlying the model that population has stable age structure (i.e. as represented by catch structure or catch at length) and constant recruitment, as well as the same mortality for all classes. For this reason, we use average of several years data for avoiding any possibility of unstable age structure as listed in the Table 2.

In regression, only points representing the decreasing abundance by successive length class are selected, while the others (smaller classes and sometime the largest class) are excluded due to the lower selectivity of fishing gear to these classes.

The estimate values of $Z$ (Table 3.) appear to be higher than the results of other studies. Widodo (1988) estimated the total mortality using the same method to be 2.15 and 3.13 for $D$. russellii and $D$. macrosoma respectively. Other estimation conducted by Dwiponggo et al. (1986) gave almost the same results.
Another method, such as mean length method which derived from Z/K quotient (Beverton \& Holt, 1956) also tend to give unreasonable results, due to mathematical artifact as the mean length of the data are very close to the length at first of capture (see also Table 1 for estimates values of $L_{c}$ ).

The formula of this method can be expressed as:

$$
\frac{Z}{K}=\frac{\left(L_{\infty}-L_{\text {mean }}\right)}{\left(L_{\text {mean }}-L_{c}\right)}
$$

where: $L_{\text {mean }}$ is the mean length of catch composition and $L_{c}$ is length at first capture.

\section{Natural Mortality}

Usually natural mortality $(M)$ is estimated by regressing $Z$ on effort of couple of years data. This method is derived from the basic formula describing the relationship between total mortality and effort exerting by the fishery (ies) that is commonly expressed as $Z=F+M$. Defining $F=q . f$, where $f$ and $q$ denote fishing effort and catchability coefficient respectively therefore $Z=q . f+M$. The intercept of this regression can be interpreted as natural mortality. In this study, we do not perform this analysis because of inconsistency of the 

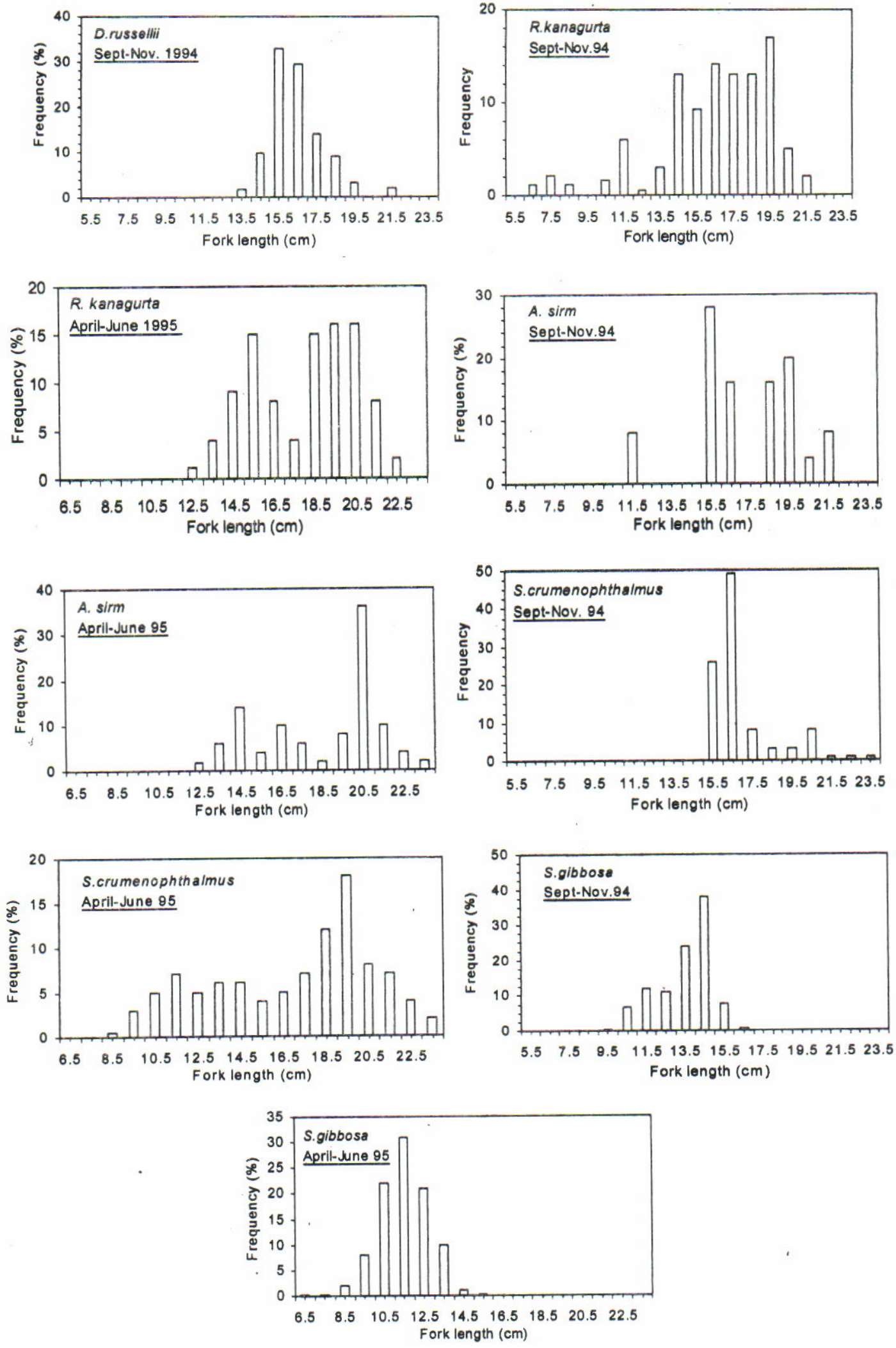

Figure 7. Histogram of length frequency of some of the main species caught by mini purse seine. 
Table 3. The mean length, $M$ and $Z$ estimates derived from catch curve method Remarks: $n$ is number of point used in regression

\begin{tabular}{lcccccc}
\hline \multicolumn{1}{c}{ Species } & Years & $\mathbf{n}$ & $\begin{array}{c}\mathbf{Z} \\
\left(\text { year }^{-1}\right)\end{array}$ & $\mathbf{r}^{2}$ & Mean length $(\mathbf{c m})$ & $\begin{array}{c}\mathbf{M} \\
\left(\text { year }^{-1}\right)\end{array}$ \\
\hline D. russellii & $1993-1994$ & 14 & 3.46 & 0.984 & 14.50 & 1.21 \\
& $1994-1995$ & 13 & 3.48 & 0.985 & 15.65 & 1.17 \\
& $1993-1995$ & 12 & 4.09 & 0.970 & 15.58 & \\
D. macrosoma & $1993-1994$ & 15 & 5.05 & 0.904 & 15.55 & 1.45 \\
& $1994-1995$ & 15 & 5.82 & 0.949 & 16.63 & 1.66 \\
S. gibbosa & $1993-1995$ & 18 & 3.67 & 0.955 & 15.57 & \\
A. sirm & $1993-1995$ & 9 & 6.78 & 0.929 & 11.25 & 1.27 \\
& $1991-1995$ & 6 & 7.32 & 0.996 & 16.57 & 1.61 \\
\hline
\end{tabular}

values of $Z$ and a difficulty in determining standard effort.

The simplest way is to apply the empirical equation of Pauly (1990) that expressed as log $M=-0.0066-0.279 . \log L_{x}+0.6543 . \log K+0.4634$. $\log T$, where $T$ is average seawater temperature in Celsius degree that is approximated to be 29 Celsius degree. The results of this estimation are listed in the Table 6.3. However, bias certainly existing as this equation is derived from different ecological areas. In this case we use this formula as rough approximation since the other methods do not give reasonable results.

\section{POPULATION STRUCTURE}

We perform Jones' length cohort analysis to investigate the structure of population by length classes for 2 species of scad (Decapterus russelli and D. macrosoma), and 2 species of sardine (Amblygaster sirm and Sardinella gibbosa) using the input data listed in Table 2.

\section{Survivors and Steady State Biomass}

As commonly produced by this method, the average number of fishes attaining successive length classes (denoted as $\mathrm{N}_{\mathrm{L}}$ ) exhibit a common phenomenon that is a tendency to follow an exponential function. No oscillation of these figures is observed for the selected species (Figure 8).

Analysis can be focused on the average number at sea (survivors) and its converted value in biomass (i.e. as defined as steady state biomass). Hence, we can evaluate the pattern of catch profile and the steady state of biomass for each species. In general, the most frequent catch by length class are not in the same pulse with that of survivors biomass, also it can be indicated that the total biomass tends to be lower than the fishery yield (Figure 9). It is clear that structure populations may not be represented by the structure of the catch and no appropriate ratio value that can be defined to indicate the representation of the population at sea from catch data.

Again, a comparison of ratio of biomass over catch of 2 Decapterus (the most dominant species in the catch) do not lead to an indication on relationship between biomass structure and their bulk catch in the fishery (Figure 10). But similar patterns are more explained by type of species, i.e. between $D$. macrosoma and $A$. sirm (within more oceanic species) and between $D$. russellii and $S$. gibbosa (within more neritic species). The patterns of the ratio are very different, for the first group of species, very low values exist in the size range representing the most frequent size in the catch. While, the patterns of another group tend to be characterized by oscillation at the common length classes and by higher value of the biomass catch ratio. For all species the biomass-catch ratio of the smaller length class are generally very high (not shown in the figures) and nothing can be described from this tendency.

\section{Fishing Mortality}

Variability of fishing mortality by length classes of the 2 species of Decapterus appears to indicate different pattern. For D. macrosoma, the highest mortality value occurs in the length class of 16 to $19 \mathrm{~cm}$, while the peak of removals lie in the smaller classes. While, the pattern of $D$. russellii is quite different with oscillation in the 16 to $17 \mathrm{~cm}$ and 17 to $18 \mathrm{~cm}$ length class during the 1993 or 1994 and 1994 or 1995 periods respectively. In order to know the influence of interval size, we attempt to enlarge it from $1 \mathrm{~cm}$ to $2 \mathrm{~cm}$ class interval (not presented in the text), but the result shows that this oscillation still exists although in lower intensity. 
$1993 / 1994$
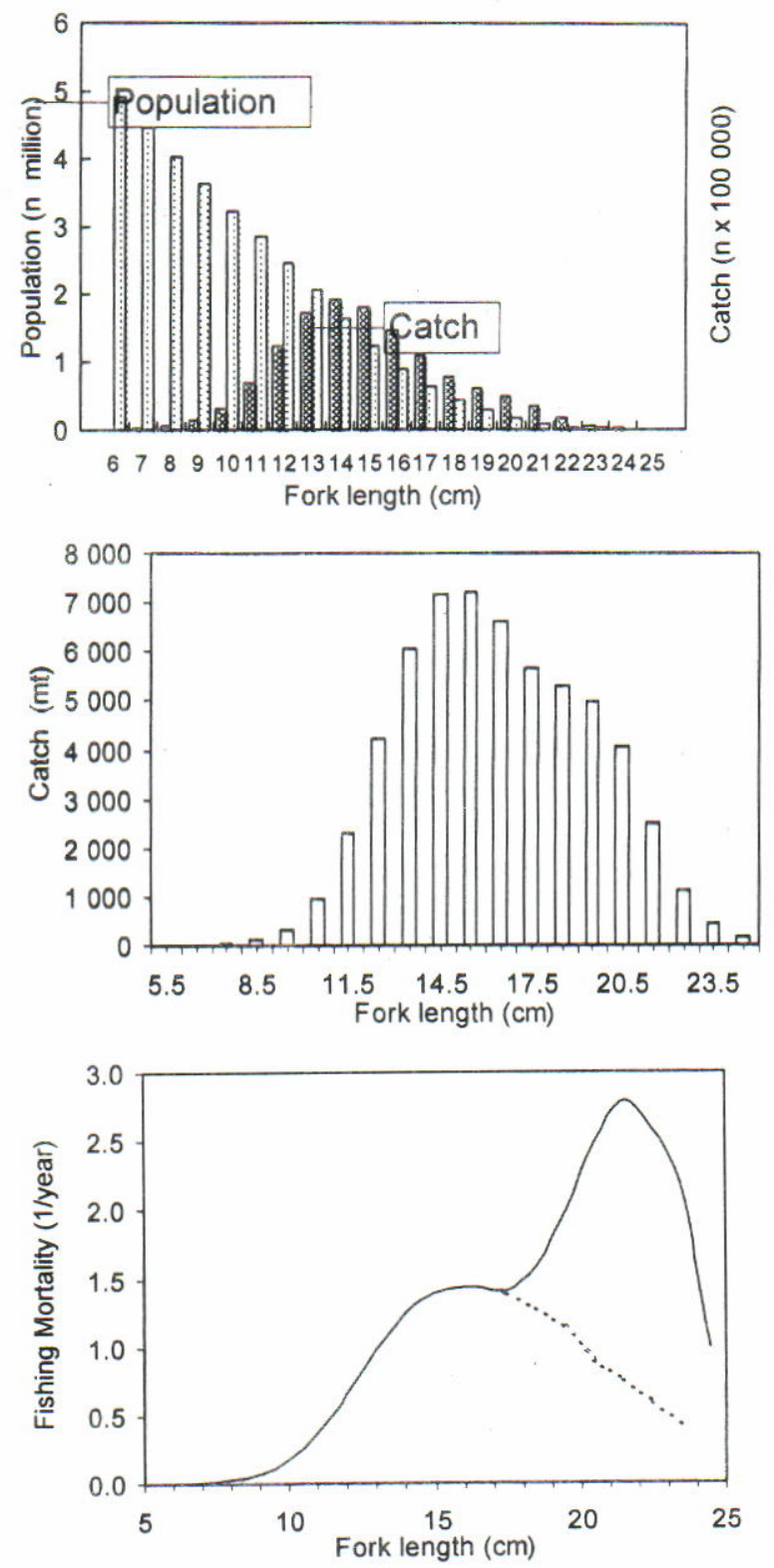

$1994 / 1995$
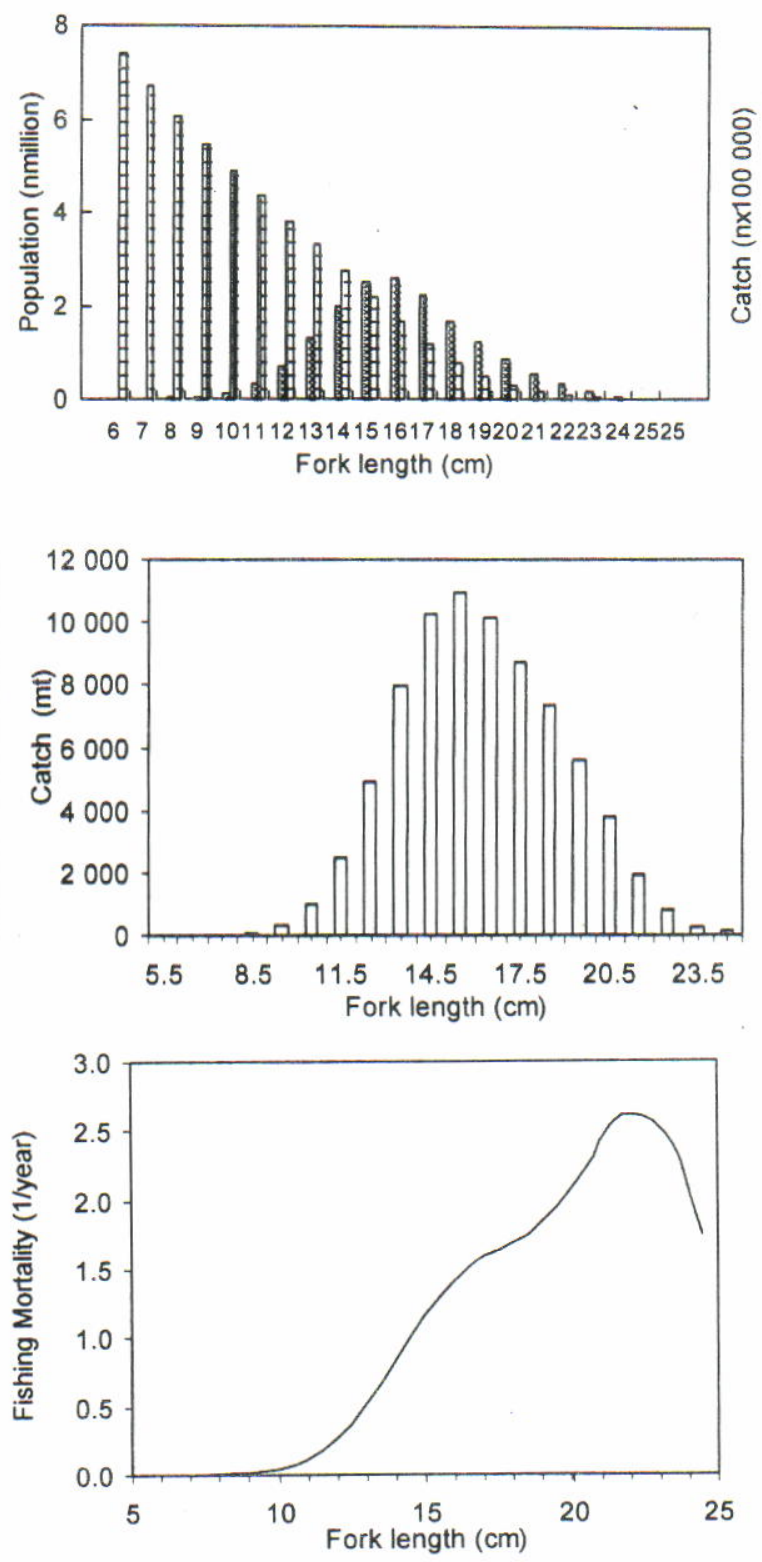

Figure 8a. Decapterus russellii: Structure of the catch and population, biomass of survival, and fishing mortality as computed by using length cohort analysis.

Similar pattern is also shown by variability of fishing mortality of $\mathrm{S}$. gibbosa (Figure 11) with oscillation point in 12 to $13 \mathrm{~cm}$ length class. In this case, the profile of catch at length data influence on the position of the highest value of $F$ or its variation. Pope (1972); Jones (1981) implicitly indicated that the value of $M$ also determining the pattern of fishing mortality by length class. We confirm it by introducing some values of $M$ (other than the estimates) which changing the mean of exploitation rate, $E(E=F / Z)$ and average value of $F$ (Table 4).

In general the rapidity of convergence of $F$ would indicate the robustness of the estimates. It can be shown that the estimates are well fitted to the data at least for three species ( $D$. macrosoma, D. russellii, and A. sirm) of which their convergent point lie before the peak of the most frequent length. 

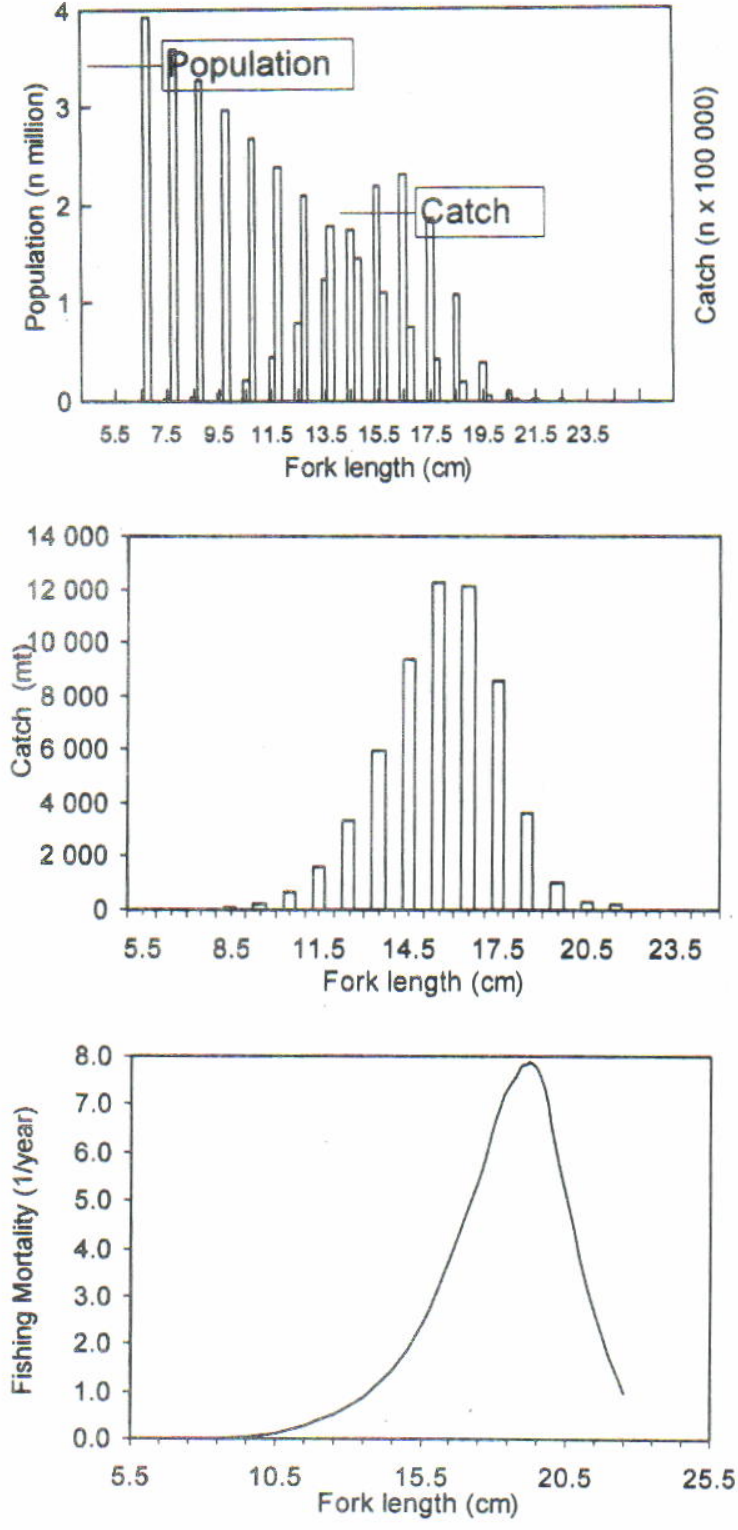
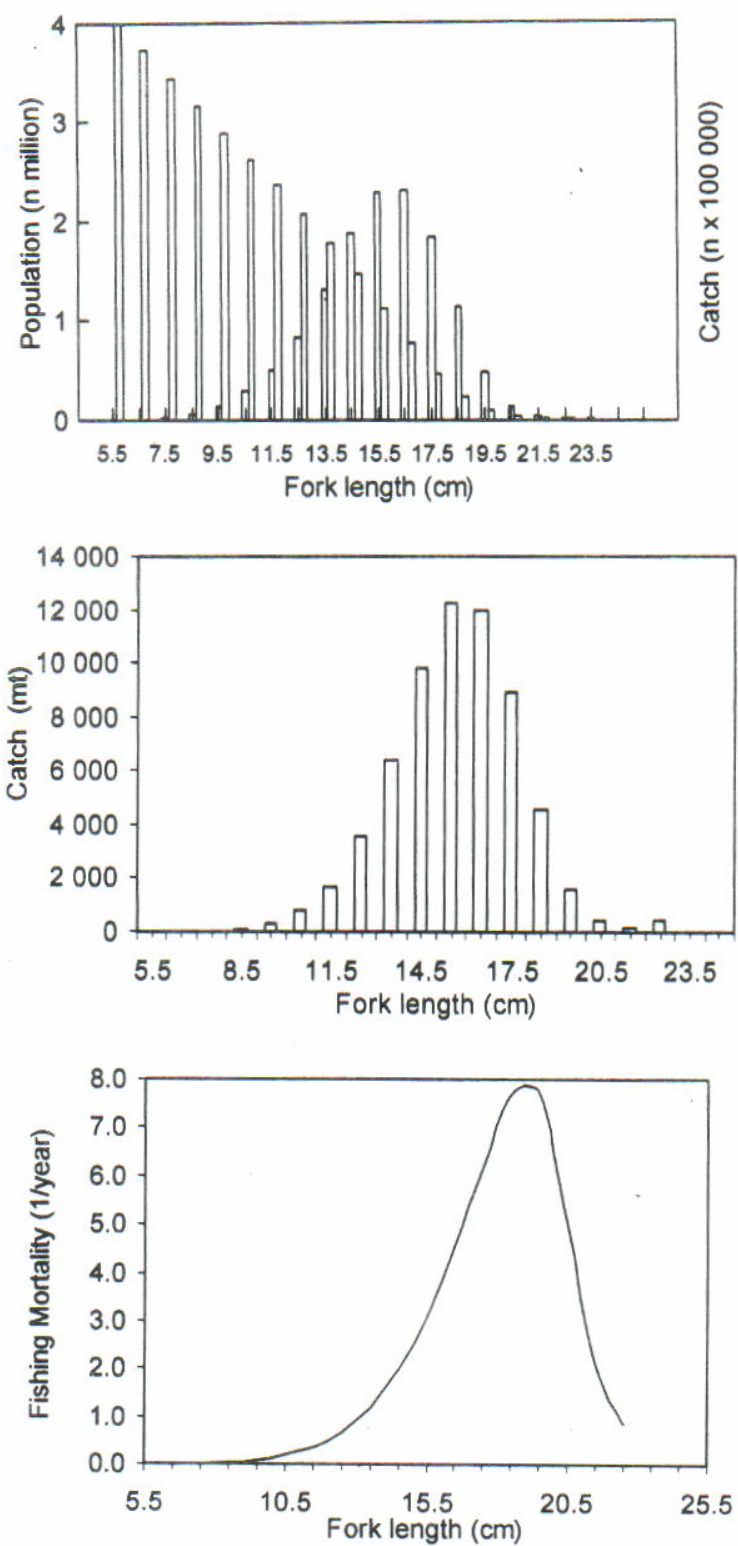

Figure 8b. Decapterus macrosoma.

\section{YIELD PER RECRUIT}

In this part, the Beverton and Holt model is employed by exerting two fisheries in the model. Natural mortality is assumed to be constant with knife edge recruitment as well as that the first fishery catches smaller size of fish than that of the second one. Further interpretation can be done by considering the fish at this size as juvenile stage. This scenario can be aimed to predict unsuccessful recruitment or high removal of young fishes, rather than to investigate the effects in the change of exploitation pattern on the yield and to define the current status of exploitation. However this type of analysis appear to be very ambitious and ambiguous, as the model is very sensitive to the change of value of $\mathrm{M}$.

The procedure can be simply implemented by simulation rather than actual data input. The first step is to employ this model with fishing mortality and age at first capture is variable at various values of F1. Any change of F1 can be expected to impact the yield of second fishery as the large part of younger stage being caught by the first fishery. The second one is to find the optimal values of fishing mortality corresponding the maximum yield per recruit at the fix values of length at first 
$1993 / 1994$

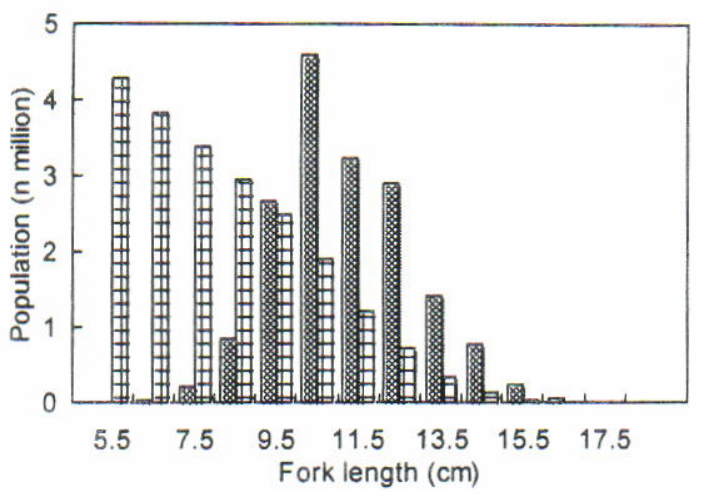

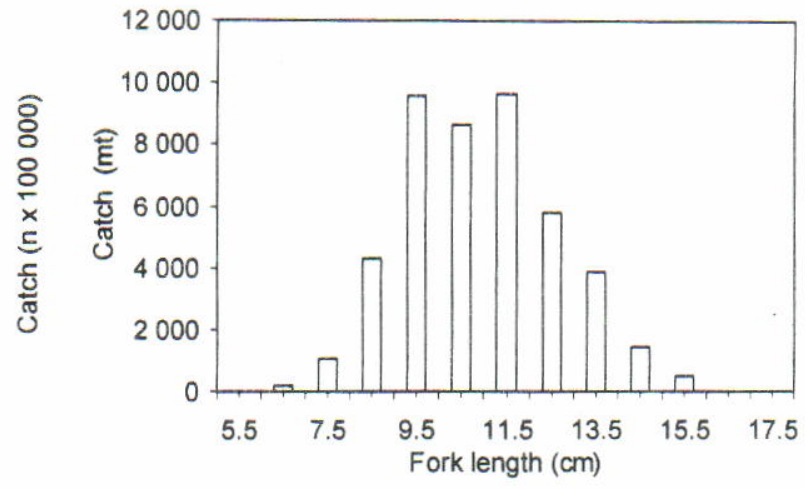

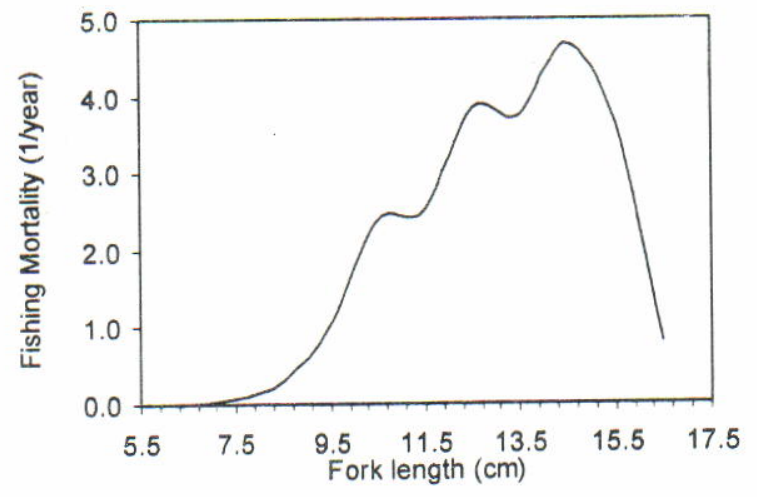

Figure 8c. Sardinella gibbosa.

capture. The concept of $F_{0.1}$ is applied if optimal $F$ ( $F$ at the yield per recruit maximum) appears to be unreasonable or too large.

\section{Interaction of Two Fisheries: A Classic Simulation}

Isopleth diagrams of yield per recruit of four main species are performed for the second fisheries (e.g. large purse seine fishery). First step is to drawn the diagrams by setting the fishing mortality of the first fishery equal to zero and the calculation will return to the ordinary model with single fishery (the first fishery is still in the model). The result indicates that the current status (in term of length at first capture) of four main species are in the optimum condition. It means that the value of length at first capture are in favorable size as the position of current Lc lie in the optimum area in the isopleth diagrams (i.e. coordinate representing combination of $F$ and LC giving highest value of yield per recruit).

Considering that the first fishery (i.e. small scale fishery) exploit the same stock at lower length at first capture than that of the large purse seine fishery. Assuming F1 about half of the mean F in computing yield per recruit seem to be more realistic although this procedure violates the validity of the model (i.e. mean $\mathrm{F}$ is computed in different assumption underlying the Jones cohort analysis). Due to unreliable estimates of length at first capture of mini purse seine fishery, we assume these values are $3 \mathrm{~cm}$ less than that of second fishery. We could use the estimate values of length at first capture of mini purse seine (as listed in Table 1), but they seem to be over estimate. Also these figures are reasonable as many small-scale fishery frequently catch these species in smaller size.

This procedure is clearly able to explained an impact of other fishery catching smaller fish size on the yield of the large purse seine fishery (that capturing larger size). The results show that an exerting of the additional $F_{1}$ in moderate level is able to shift the optimum area to lower values, without changing significantly their shape. In fact, the increase of $F_{1}$ is followed by slightly increase of total yield per recruit, but lowering the yield of the second fishery (right hand side of the Figure 12 to 14).

\section{Optimum F}

Optimum $F$ usually is defined as a value of $F$, which give the maximum yield. It can be estimated 
Decapterus russellii (1993 to 1995)

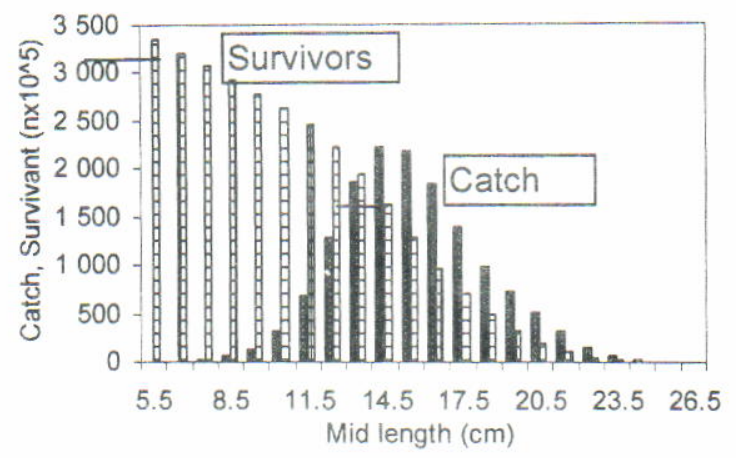

Decapterus macrosoma (1993 to 1995)

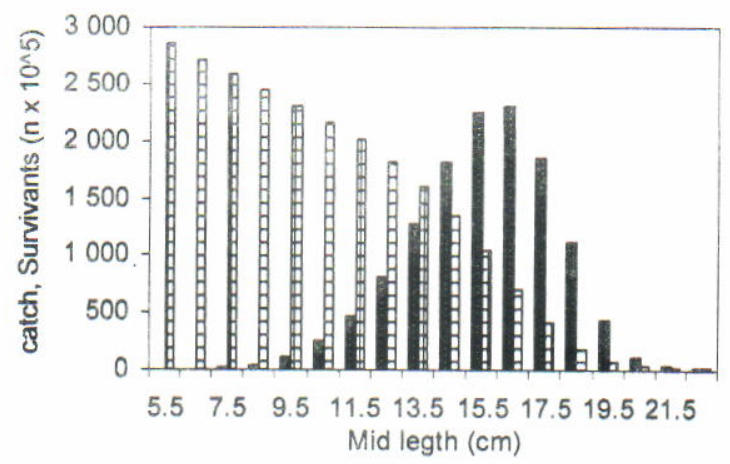

Amblygaster sirm (1992 to 1995)

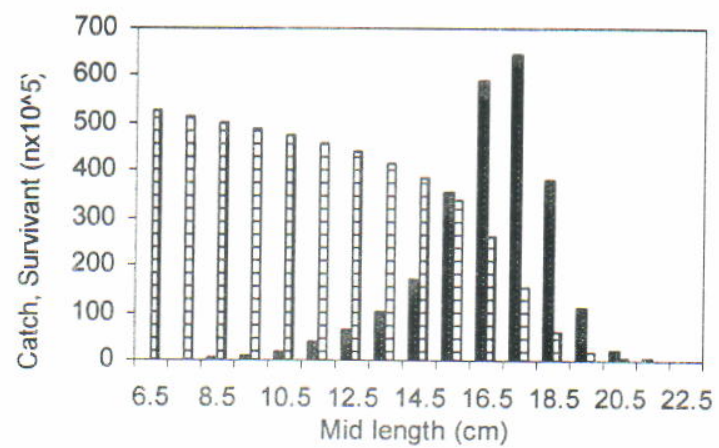

Sardinella gibbosa (1993 to 1994)
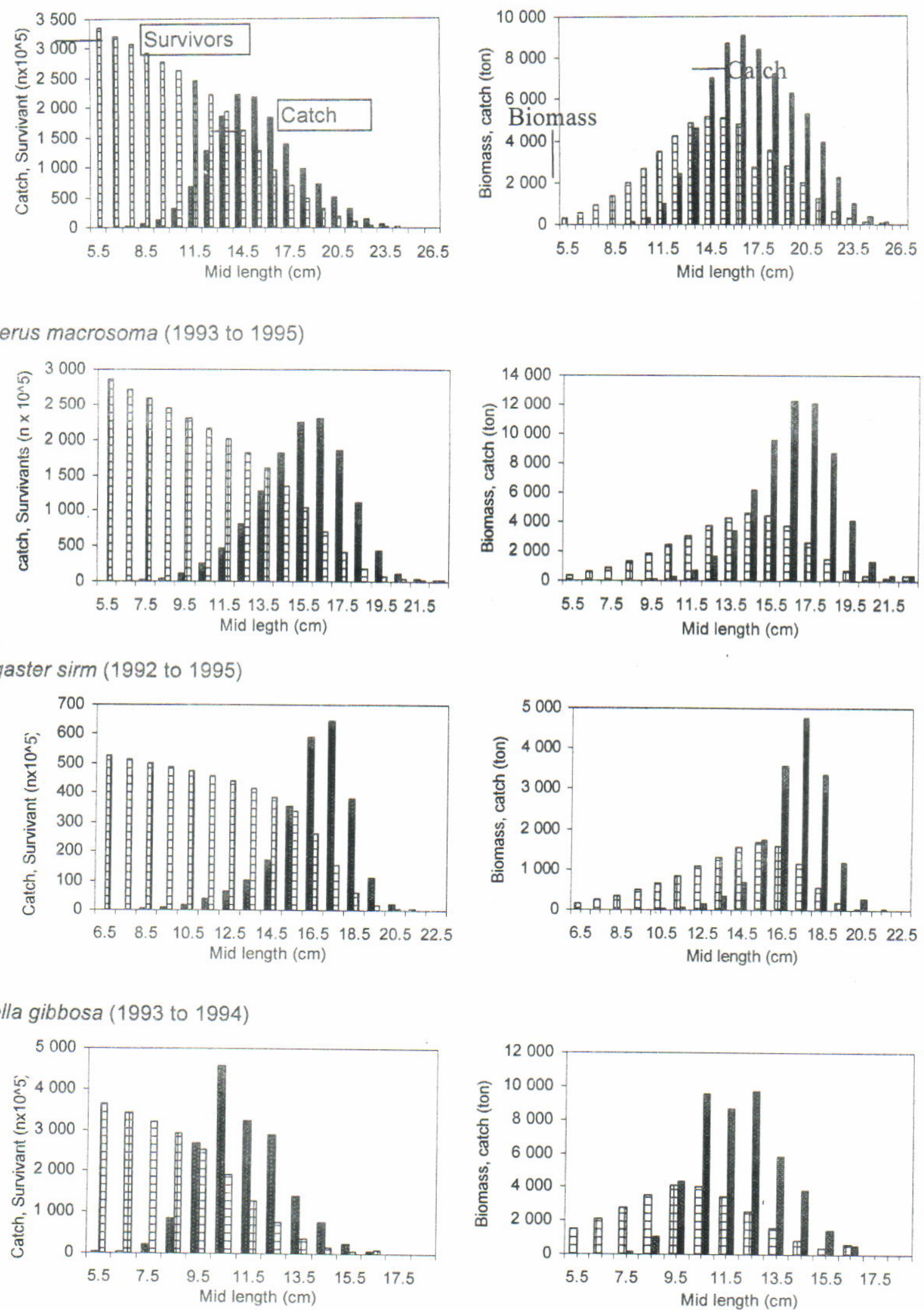

Figure 9. Structure of population and catch of four pelagic species at various periods of samplings 
a. D. russellii

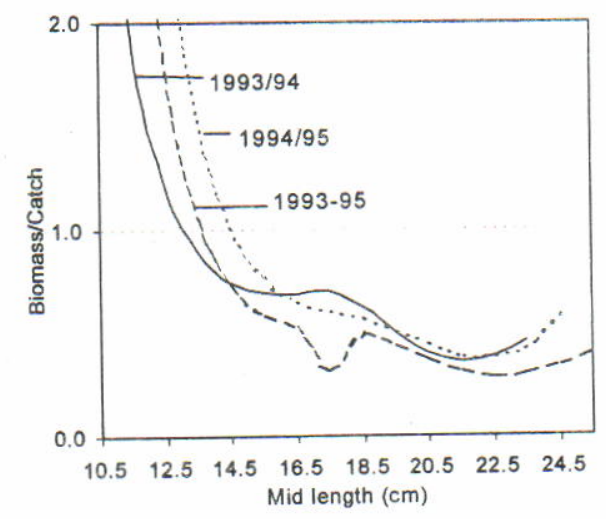

C. A. sirm

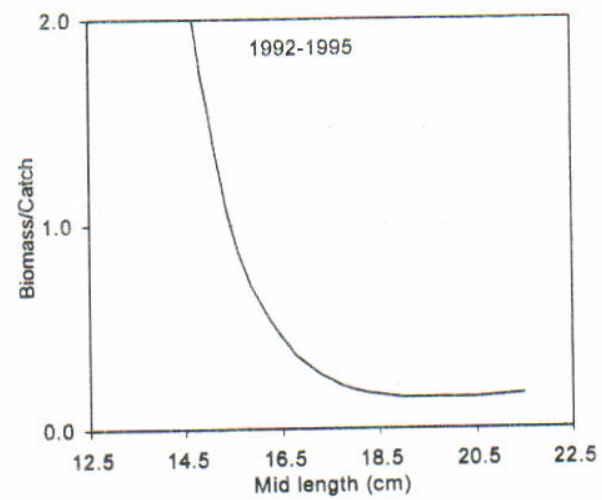

b. D. macrosoma

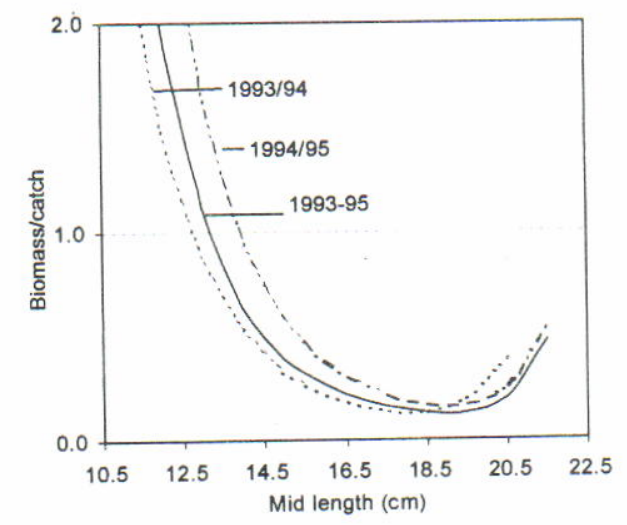

d. S. gibbosa

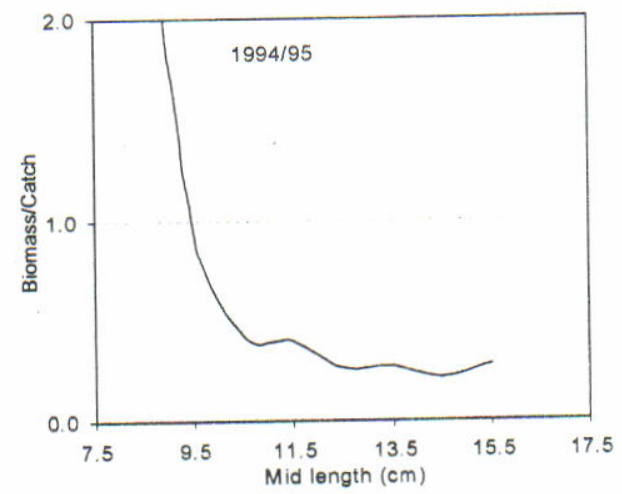

Figure 10. Ratio of steady state biomass-catch of four main species at various periods.

Table 4. The mean of exploitation rate (mean $\mathrm{E}$ ) and $\mathrm{F}$ derived from length cohort analysis Remarks: in bracket denote as arbitrary values

\begin{tabular}{lccccc}
\hline \multicolumn{1}{c}{ Species } & Years & Mean F & Mean E & $\begin{array}{c}\text { M } \\
\text { (year }{ }^{-1} \text { ) }\end{array}$ & $\begin{array}{c}\text { Biomass } \\
\text { /Catch }\end{array}$ \\
\hline D. russellii & $1993-1994$ & 0.43 & 0.26 & 1.21 & 0.93 \\
& $1994-1995$ & 0.38 & 0.22 & 1.17 & \\
& & 0.63 & 0.51 & $(0.6)$ & 0.89 \\
& $1993-1995$ & 0.49 & 0.29 & 1.19 & \\
D. macrosoma & & 0.55 & 0.56 & $(0.6)$ & 0.74 \\
& $1993-1994$ & 0.68 & 0.32 & 1.45 & 0.61 \\
A. sirm & $1994-1995$ & 0.82 & 0.0 .33 & 1.66 & 0.42 \\
S. gibbosa & $1993-1995$ & 0.53 & 0.28 & 1.55 & 0.53 \\
& $1991-1995$ & 0.35 & 0.17 & 1.61 & 0.73 \\
& & 0.50 & 0.33 & $(1.0)$ & 0.61 \\
& $1993-1995$ & 0.84 & 0.4 & 1.27 & 0.61 \\
& & 0.72 & 0.42 & $(1.0)$ &
\end{tabular}

by performing the model at given length at first capture and $M$. In our case, the input parameter values are considerably high (i.e. M), although the current length at first capture lies in the optimum area (in the isopleth diagram). In this case, the maximum value of yield does not exist or not reasonable, because the yield curve is very flat with very high value of $F$ at maximum yield $\left(F_{\max }\right)$
(Figure 15 and 16). For this reason, we apply the concept of $F_{0.1}$ to overcome this mathematical consequence of the use of high input value of $M$ and LC. This concept of $F$ rate at $F_{0.1}$ has become widely applied as management criteria in some regions, such as in the Atlantic fisheries in the Canadian Economic Exclusive Zone (Doubleday et al., 1984). 


\section{a. Decapterus russellii}

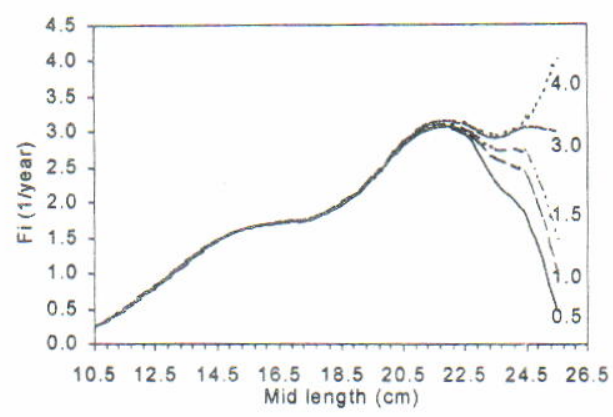

c. Amblygaster sirm

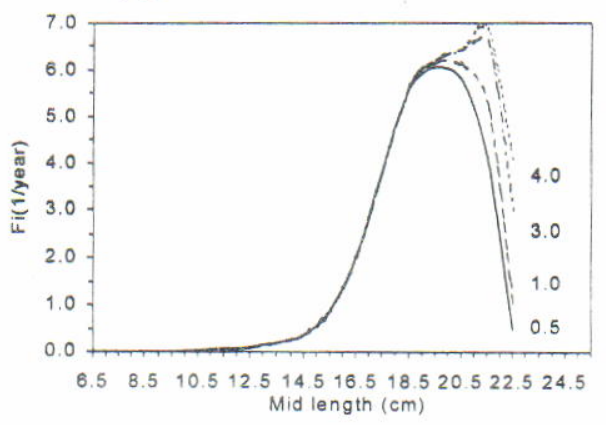

b. Decapterus macrosoma

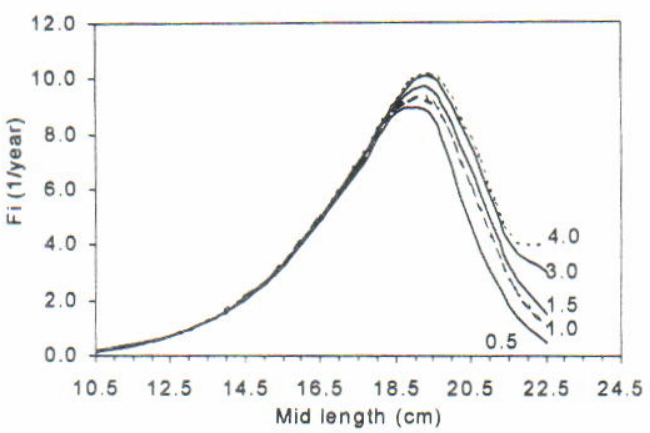

d. Sardinella gibbosa

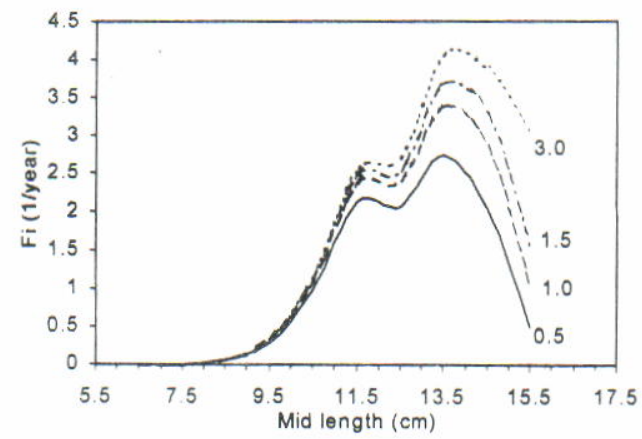

Figure 11. Trend of fishing mortality at successive midlength at various input of $F_{\text {-terminal. }}$. Remarks: Figures inside the graphs denote the input value of $F_{\text {-terminal }}$

The advantage of this criteria is that $F_{0.1}$ is always lower than $F_{\max }$ and applicable to the flat curve phenomenon being generated by high value of $\mathrm{M}$ and Lc (i.e. $\mathrm{F}_{\max }$ would be very large). We simply estimate the $F_{0.1}$ by eye from the yield curve rather than applying theoretical formula. We perform this procedure to calculate $F_{0.1}$ for two species of Decapterus. Approximate values of $F_{0.1}$ of the two Decapterus are listed in the Table 5.

Taking the value of $\mathrm{M}$ as 1.19 and 1.55 year $^{-1}$ (Table 4 ) for $D$. russellii and $D$. macrosoma respectively, the calculated value of $E_{0.1}$ would be greater than 0.50 for the lowest estimate $F_{0.1}$ (i.e. 1.4 and 2.0 year $^{-1}$ for $D$. russellii and $D$. macrosoma respectively). These rough approximations appear to be in good agreement with the results of Widodo (1988). He found the values of $E_{0.1}$ are slight higher than that derived from the lowest approximate values of $F_{0.1}$. The methods used are different, in this study an approximation is applied rather than performing direct calculation of $F_{0.1}$ or $E_{0.1}$. We believe that the variation of estimates is strongly influenced by the input value of $M$. As the value of $M$ can not be precisely estimated, the estimate value of $F_{0.1}$ and $E_{0.1}$ should be aimed to give a general description on the state of exploitation.

It is reason why we avoid evaluating the stock being based on the inappropriate input. However, the use of a range of the input of $M$ may be promisable, and can be hoped to describe general condition of the stocks at low accuracy. Instead of using the range of $M$, the rough approximate of $F_{0.1}$ would be analogous to the use $M$ as variable. This would result more and less the same variation of yields estimates.

The analysis performed in this part has two drawbacks, since the assumptions seem to be difficult to achieve. The first one, which is one part of the stocks (of the same population), is exploited by the Javanese fisheries of which the data were

Table 5. Input parameters and approximate values of $F_{0.1}$ of $D$. russelli and $D$. macrosoma

\begin{tabular}{lccccccc}
\hline \multicolumn{1}{c}{ Species } & LC large seiner & LC other fishery & $F_{\text {other fishery }}$ & Y/R max & Appr. $F_{0.1}$ & $E_{0.1}$ & $E_{0.1}{ }^{2}$ \\
\hline D. russellii & $11.5-14.5 \mathrm{~cm}$ & LC large seine $-3 \mathrm{~cm}^{*}$ & $0^{*}$ & indefinite & $\sim 1.4-2.0$ & $>0.54$ & 0.57 \\
D. macrosoma & $11.5-15.5 \mathrm{~cm}$ & LC large seine $-3 \mathrm{~cm}^{*}$ & $0^{*}$ & indefinite & $\sim 1.6-2.3$ & $>0.51$ & 0.55 \\
\hline Remarks: ${ }^{*}=$ assumed values; ${ }^{2}=$ Widodo, 1988 & & & & &
\end{tabular}


collected from. The second one, the validity is obscured by ecological phenomena that is not included in the model such as false growth oscillation induced by seasonal migration activity. In the analysis we use conversion formula of oscillation growth that is facilitated in the Fisat software and in our computation of yield per recruit, but the models do not include the removal being caused by emigration of the adult fishes.

The unclear result as mentioned above may be caused by several factors. Recall to the previous chapter, that migration of the dominant species (i.e. D. russellii and $D$. macrosoma) play an important role in determined the repartition of size and shoal pattern formed by the species. In relation to the seasonal pattern of seawater properties (especially, salinity) and the east west gradient of salinity, the migration tends to follow this environmental gradient pattern. It will give an immediate impact on spatial distribution of fish size. This pattern has been known by the fishermen, and their knowledge on the migration has well developed, but it is valid only for the stock inside the Java Sea, while the data from other area are not available at this time. Finally, the length composition data represent only the structure of stock exploited in the Java Sea area.

Ignoring the accuracy on the natural mortality estimation, the validity of model applied in this study may need an adjustment due to this phenomenon. Theoretically (e.g. based on the mathematical formula), the drop of the number of frequency of the big size in the catch precisely cause a lower estimate of the number of fish attaining this range size, as manifested by the lower biomass-catch ratio. As described in the previous chapter, an emigration of the most of large size class to other areas beyond fishing ground of purse seine is obvious.

In this case, the modification of the VPA model should involve an effect of the emigration and immigration during southeast monsoon period. This effect would be strong because of its influence on the input data structure and input parameter (e.g. growth rate). Inserting a function replacing exp (M/2) term for representing the effect of seasonal catches (Mertz \& Myers, 1996), but it seems to be an unclear approximation since the problem in quantification of that factor has not been solved yet in this study. Another solution has been proposed by regarding the model as an approximation to more general conditions when fishery varies continuously during the year (Kizner \& Vasilyev, 1997). These amended models, however, never consider the effect of migration, although the last one gives an option of zero catch that may be analogous to the undeterminable catch. It would arrive to another question related to the definition of catches as removal. In this case, removals from the Java Sea equal to the real catch plus emigrants. Our data shows that the majority of the catch consists of progeny of different class exist in the last year period. Empirically, there is no agreement between the age derived from back calculation of the pulse of recruitment and calculated of date of birth from the period of the occurrences of the highest value of IGS. However, no method has been developed to model this type of emigration process.

Other constraint of application of this method is related to the data acquisition in the official level. Until recent year there is no reliable statistical data available from the provinces out side the Central Java Province. The basic system of statistical data collection is the same for all provinces but the tradition of data recording is really different. Unfortunately, this study is not concerned to this problem as the project objectives are more focused on the Java Sea. Citing from the report of Directorate General of Fisheries may arrive at a substantial biases, as the tendency of an optimistic increase of landing at certain level (i.e. around 4 to $6 \%$ per year) whatsoever the condition of the fisheries.

Evaluation using another approach (yield per recruit model of Beverton and Holt) faces the problem of the input value of natural mortality (M). The influence of different $M$ on the calculated yield (yield per recruit) appears to be important, due to the validity of the estimate $M$, a general description on the optimum fishing mortality maybe calculated at given range of value $M$.

A solution by applying the concept of $F_{0.1}$ to avoid the undeterminable optimum $F$ may be an artificial even though this technique successfully applied in this study. Unfortunately, the accuracy of estimate maybe very low, as the range of $F$ optimum at different value of $L C$ and $M$ are wide for the two Decapterus, although these values cover the results of previous study of Widodo (1988). But, it may pose a question relating to development of the exploitation. Is the state of exploitation in 1993 to 1995 lower than that in 1986 ? This question should be in relation with historical development of the javanese purse seine fishery. As indicated by other studies (Potier \& Sadhotomo, 1995), the dramatic increase of the development (i.e. investment) of the purse seine fishery was begun in the year 1986 as marked by new investment on the bigger boats. This 
a. 1993 or 1994
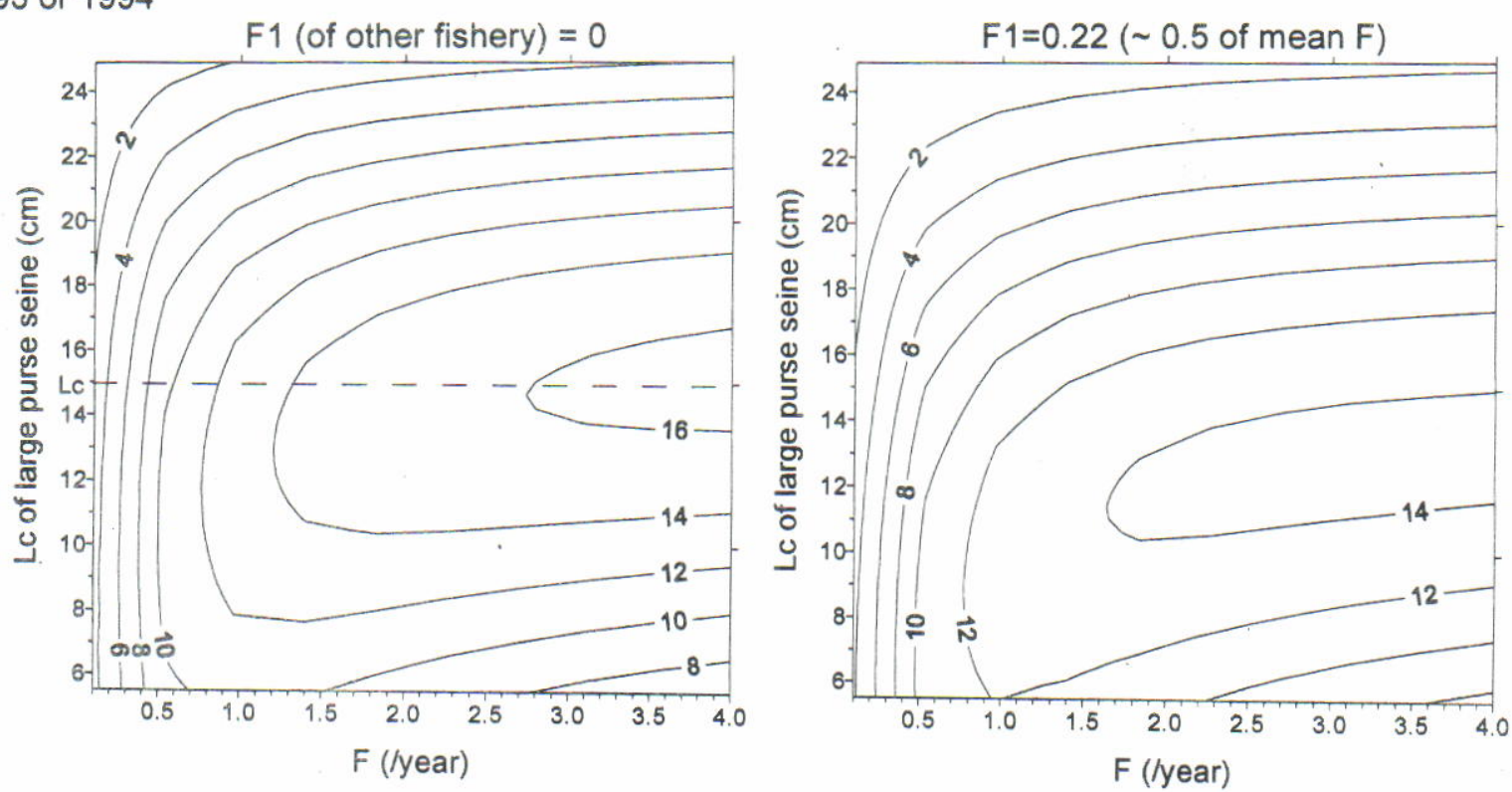

b. 1994 or 1995
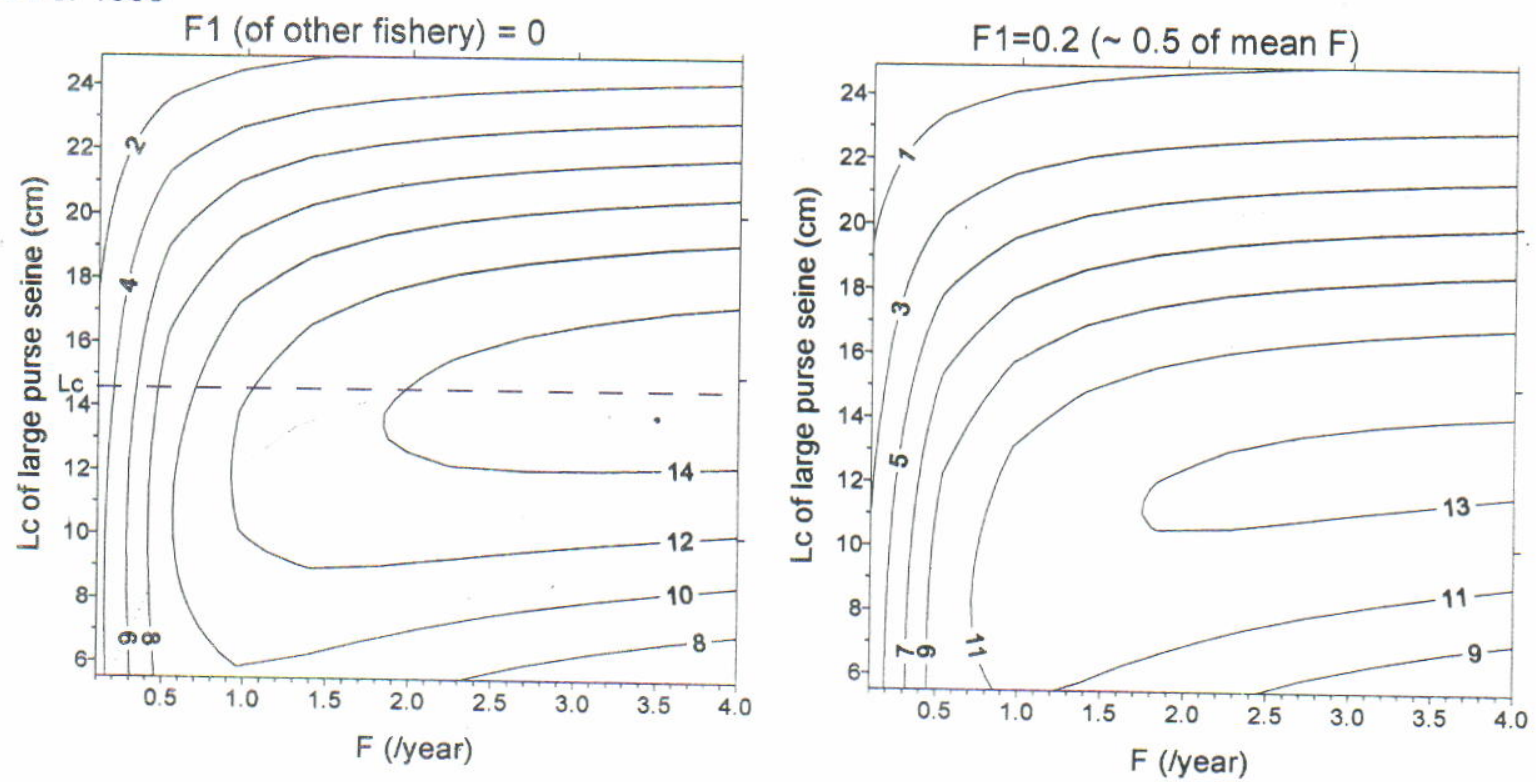

Figure 12. D. russellii: Isopleth diagram of yield per recruit for large seine fishery. The left side is at Lc assumed to be $10.5 \mathrm{~cm}$.

Remarks: figures inside the graphs denote values of yield per recruit in unit of $\mathrm{g}$

phenomenon may be triggered by the enormous abundance of pelagic fish disponible at the year 1985 being induced by interannual variability of the climatic phenomena. However, one year would be too short to generate drastically increașe of fishing effort, and from this period the investment had been going on until 1993 to 1995 .

It is clear that the removal of layang (due to exploitation) in 1986 was lower than that of 1995 . It means that fishing mortality in the recent years are greater than those of previous periods.

Again, it will back to the accuracy of estimate, in this case, the model used and the input parameters. We can notice that our sampling scheme is more comprehensive than other studies have ever been made for the same stocks. The most important source of the possible bias of estimate is the spatial distribution of the fish size in 
a. 1993 or 1994
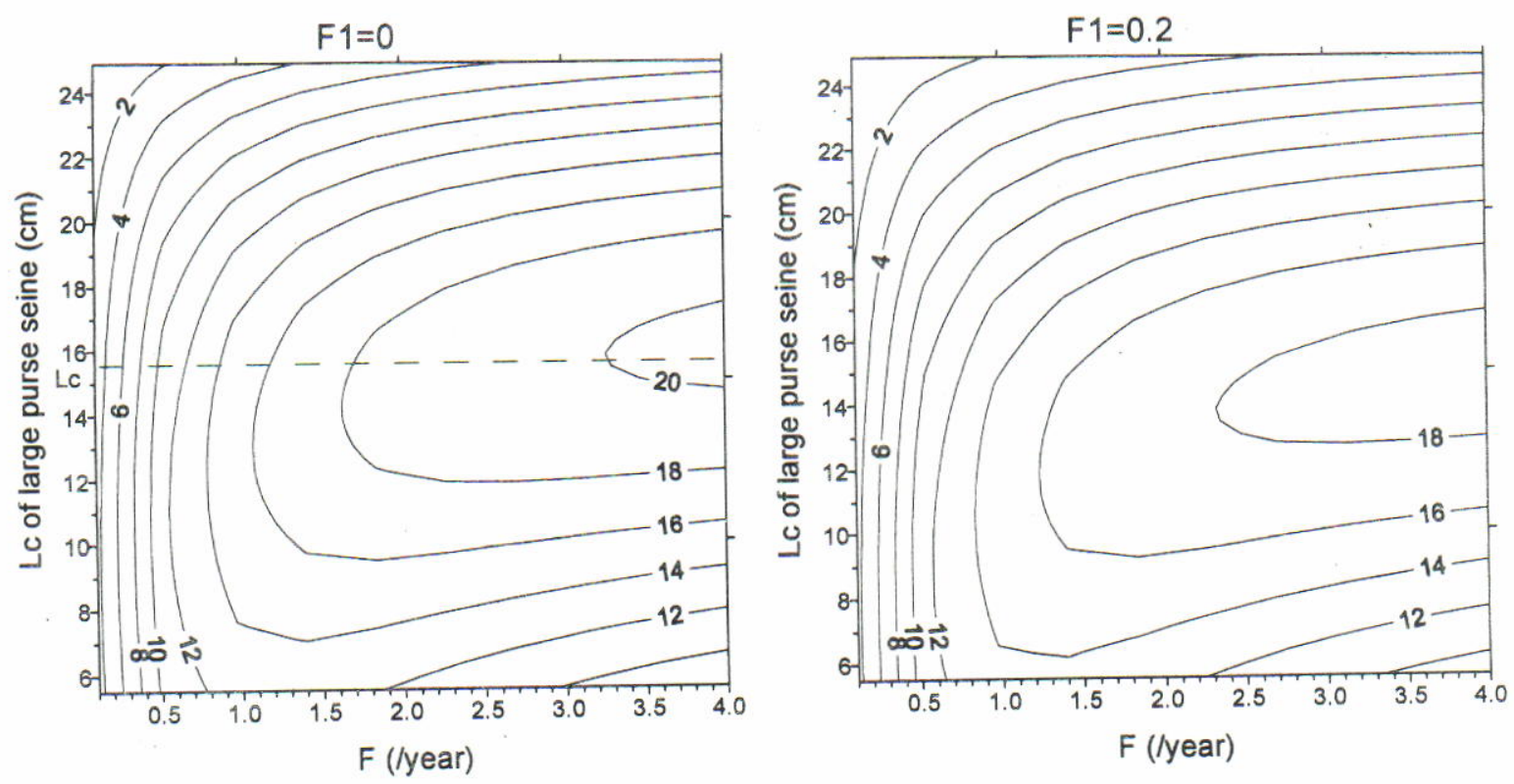

b. 1994 or 1995
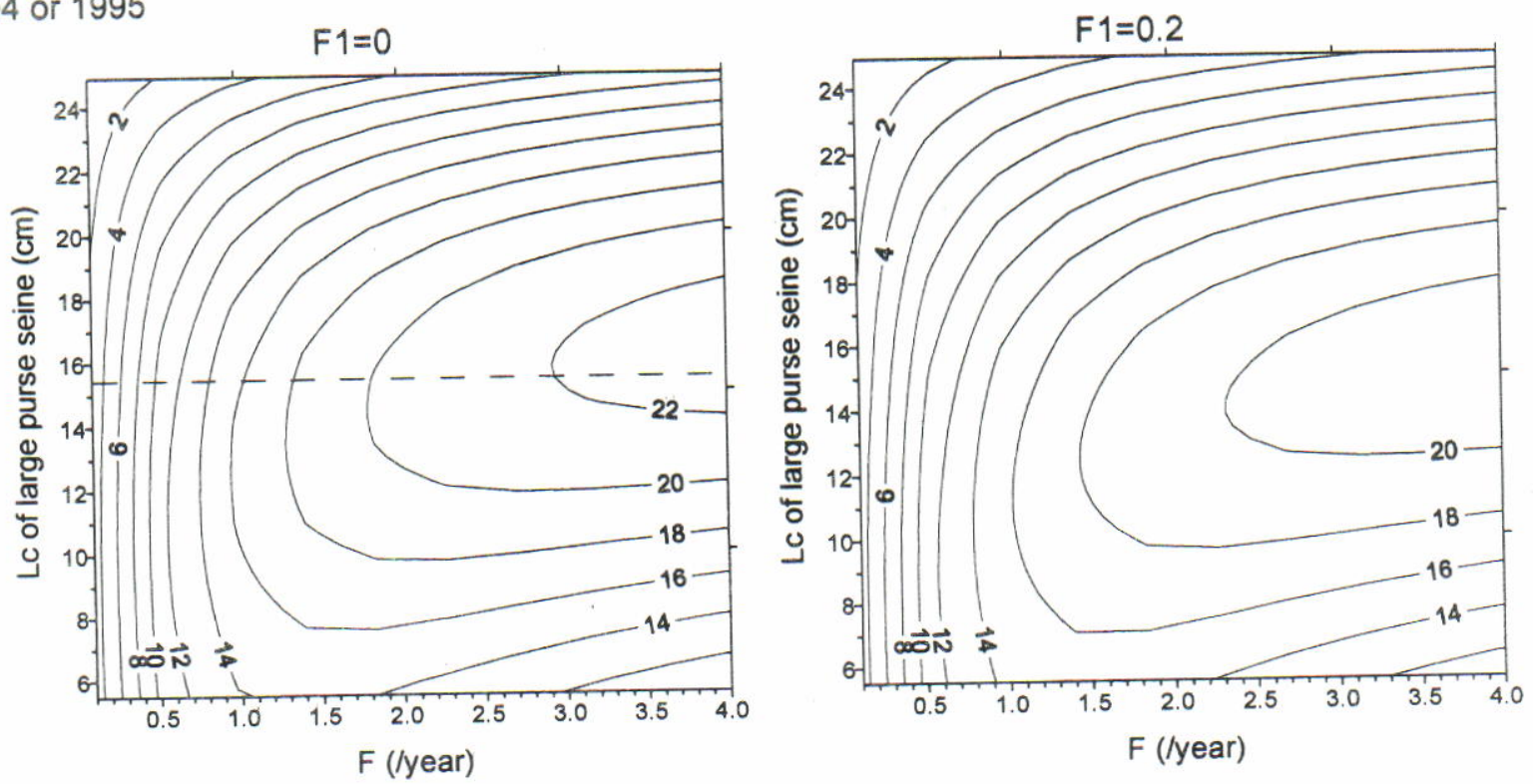

Figure 13. D. macrosoma: Isopleth diagram of yield per recruit for large seine fishery. The left side is a absence of other fishery; the right hand side is showing the impact of other fishery with assumed to be $12.5 \mathrm{~cm}$.

the same fashion as mentioned for the first approach.

If the values of $F_{0.1}$ estimates can be assumed to be well estimated i.e. no violation to the model, it will be unfortunated by the lack of conversion factor to the standard effort. However, information on the fishing effort are not available for this study, detailed description are presented in Potier in press. Nevertheless, this model has an advantage in modeling the impact of exploitation on the juvenile stages. 
a. A. sirm, 1992 to 1995

$$
F 1=0
$$

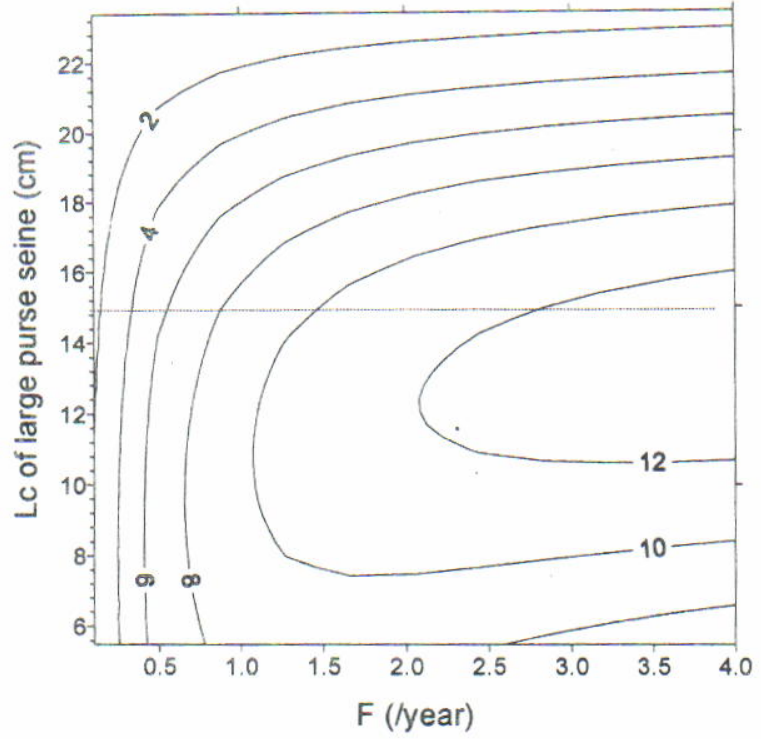

b. S. gibbosa, 1993 or 1994

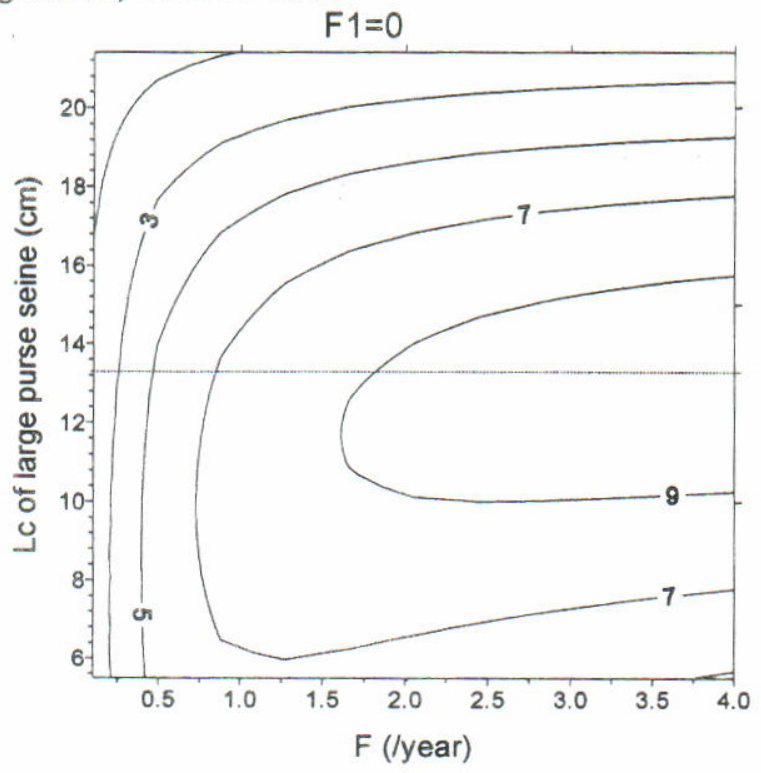

$F 1=0.3$
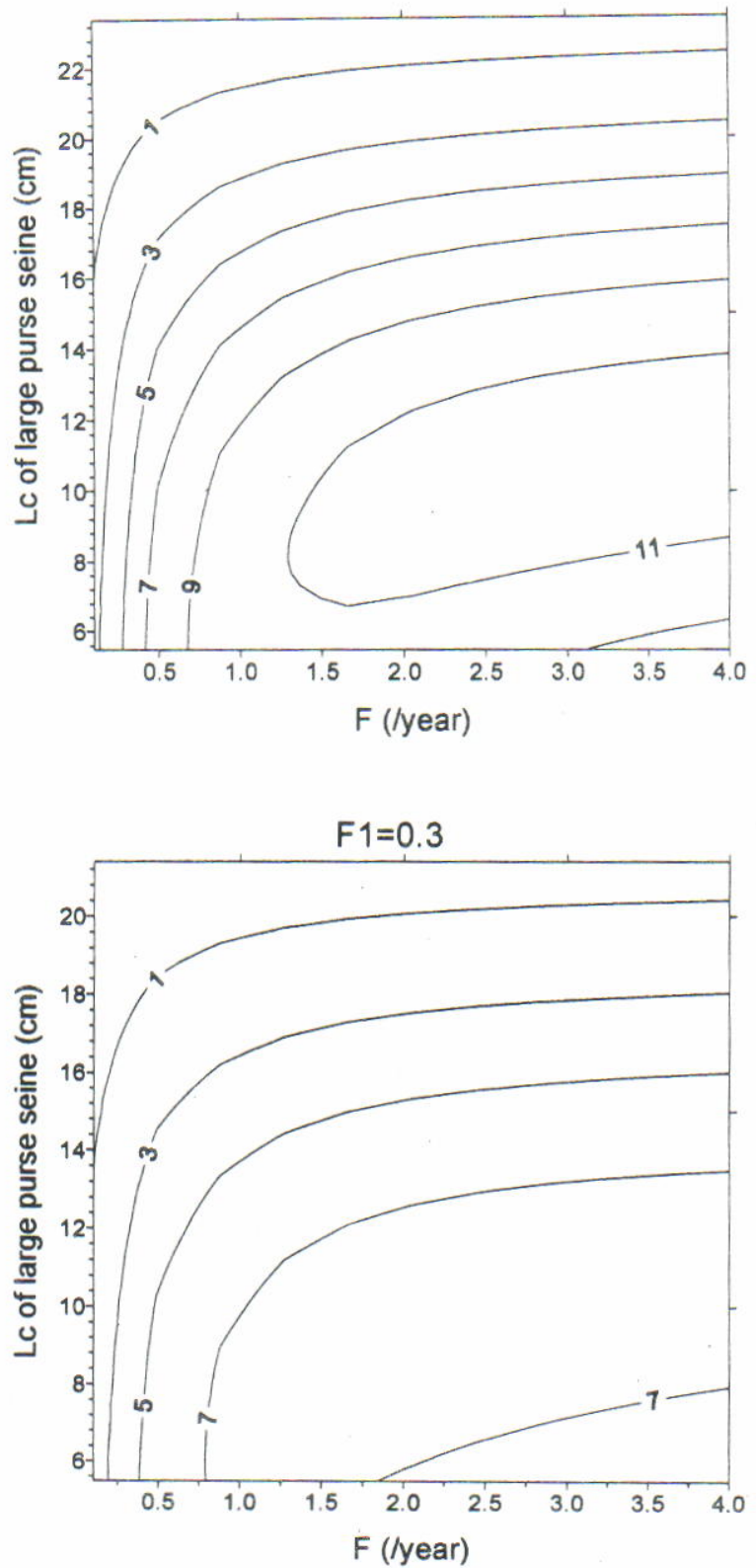

Figure 14. A. sirm \& S. gibbosa: Isopleth diagrams of yield per recruit for large seine fishery. The left side is at an absence of other fishery, the right hand side is showing the impact of other fishery with Lc assumed to be $10.5 \mathrm{~cm}$ for A.sirm and 8.5 for S. gibbosa. 
a. $Y / R$ at fix LC of large seine $=15.5 \mathrm{~cm}$ and various values of $M$

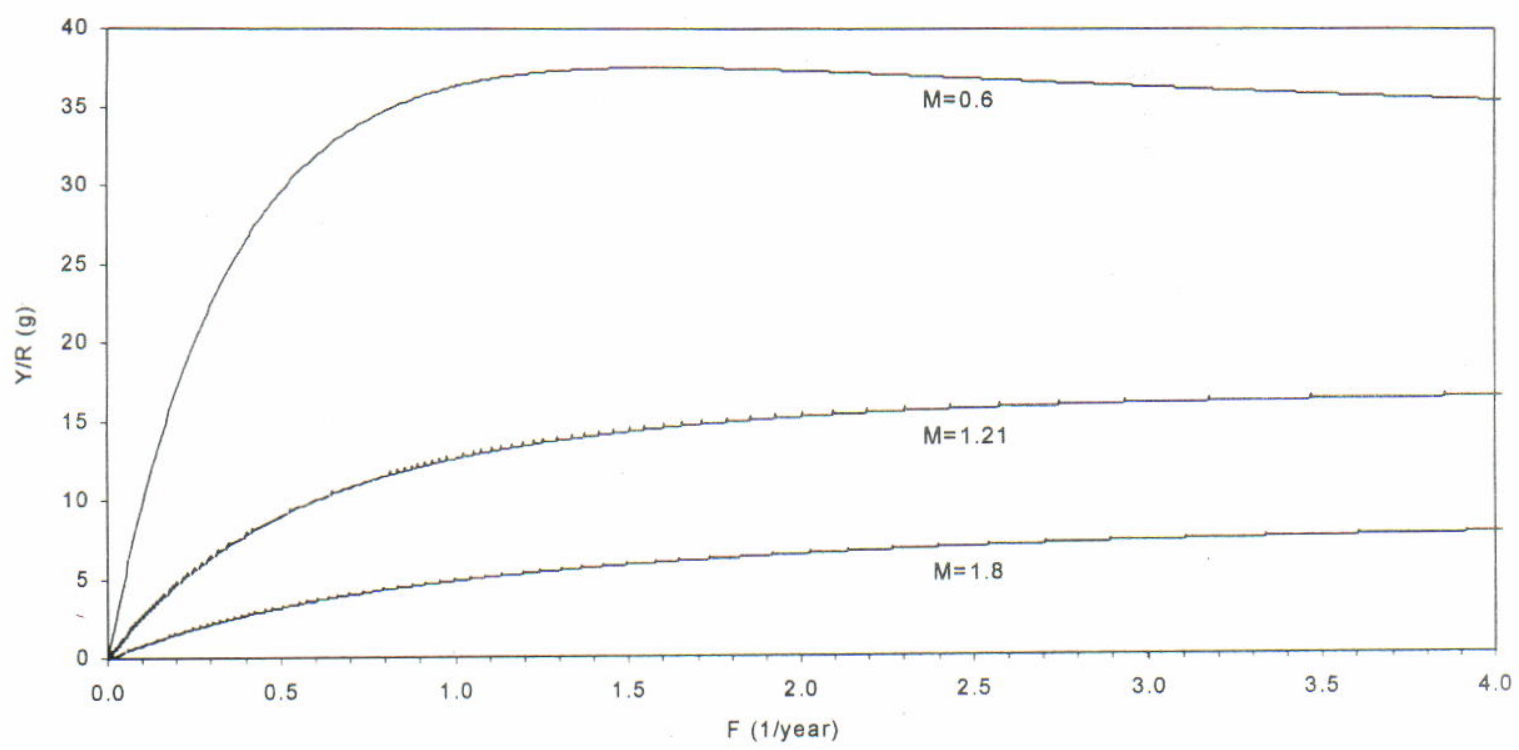

b. $Y / R$ at fixed $M=1.21$ and various values of $L C$ of large seine

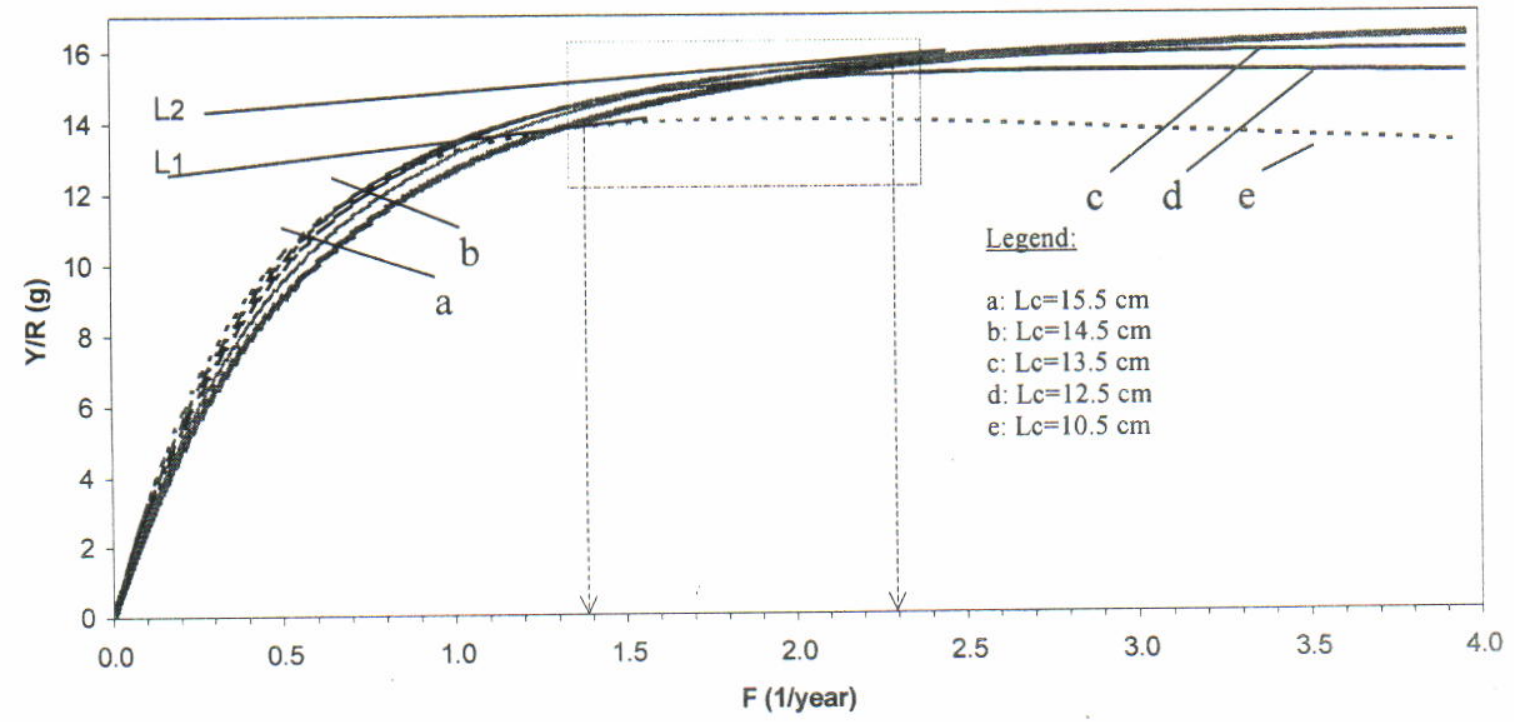

Figure 15. Yield per recruit of $D$. russellii at various values of $M$ and $L C$, based on estimate parameters of 1993/1994. L1 and L2 denote lines parallel to line of $F_{0.1}$ at $L C=10.5$ and $15.5 \mathrm{~cm}$ respectively. Shadow area is showing the approximate range of points at tangents lines. 
a. $Y / R$ at fix LC of large seine $=15.0 \mathrm{~cm}$ and various values of $M$

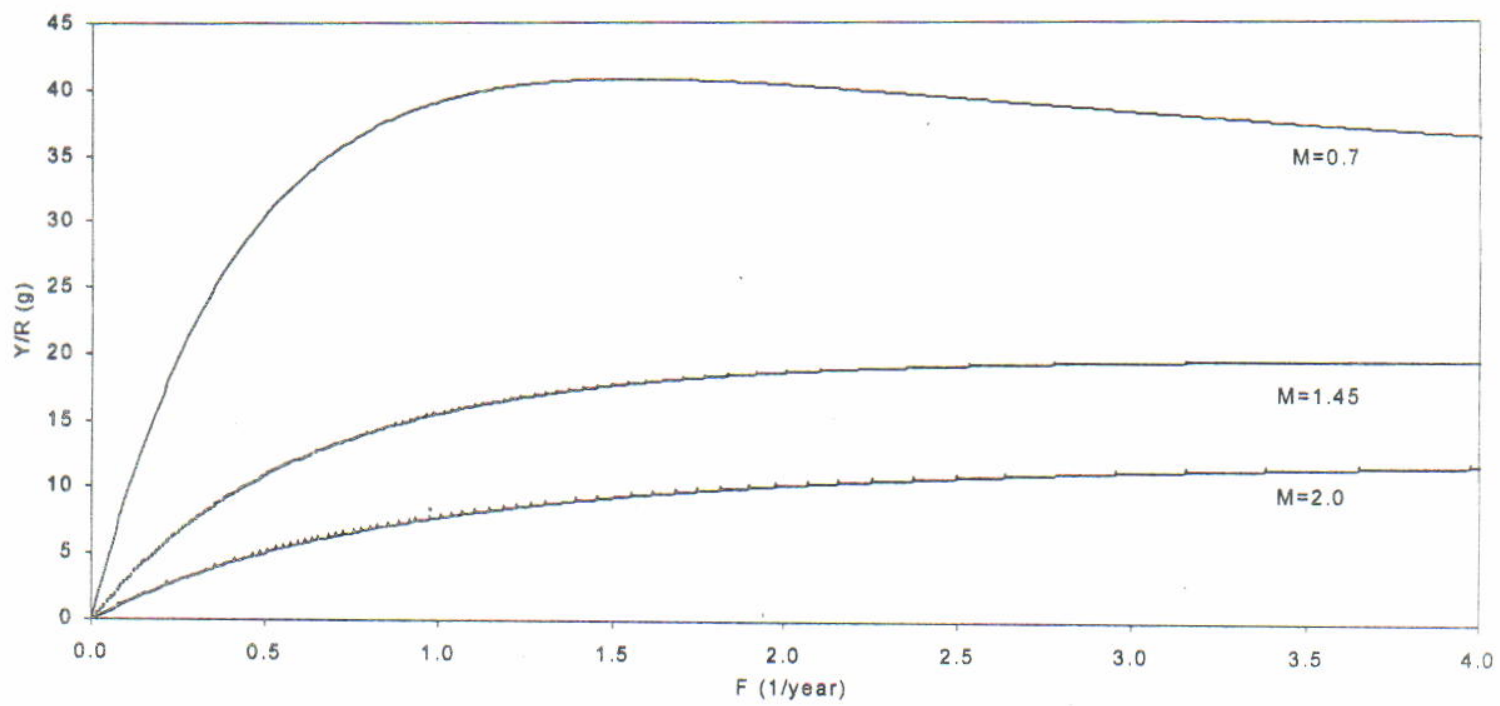

b. $Y / R$ at fixed $M=1.21$ and various values of $L C$ of large seine

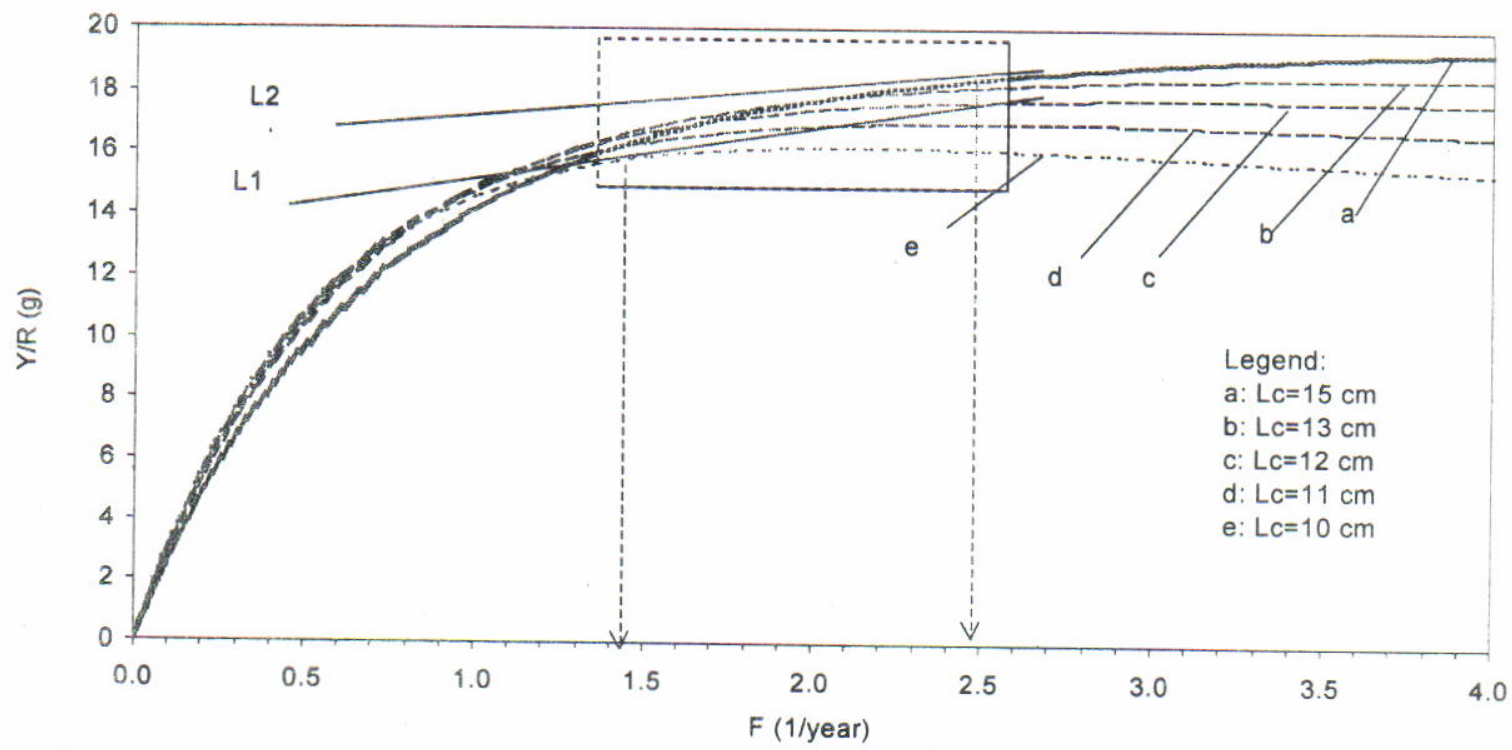

Figure 16. Yield per recruit of $D$. macrosoma at various values of $M$ and $L c$, based on estimate parameters of 1993 or 1994. L1 and L2 denote lines parallel to line of $F \quad 0.1$ at $L C=10.0$ and $15.0 \mathrm{~cm}$ respectively. Shadow area is showing the approximate range of points at tangents lines.

\section{CONCLUSION}

Due to inaccuracy of mortality estimates and uncertainty of interpretation being caused by the lack of quantitative information on the migration and repartition of the populations, conclusion maybe drawn by emphasizing on the qualitative manner of the results.

At the current state, more than 50 percent of catch consist of young fish or in other word, length at first capture of the main species are lesser than length at first maturity. It means that most of fish stayed in the exploitable area of the Java Sea is consisted of young fish (around one year old). Considering the emigration activity of the adult fish, both the number of fishes harvested by fishing must compose the removal and those emigrate to the eastern archipelago. But, no quantification of their proportion can be determined in this study. In this case, by holding the assumption that no emigration can be considered, the mortality of the size larger than of length at first capture of the migrant species (especially for genus Decapterus) is notably high. 
The removal as expressed in the number and weight of fishes captured are higher than the survival.

Theoretically, there is an impact of the exploitation on the young fish by small scale fishery on the semi industry fishery yield. The degree of interaction between two fisheries would be not so important, as the exploitation on the young stage by small scale fisheries is considerably weak, at least, as shown by total yield of the two fisheries.

Under the current assumption and input parameters values introduced in the model, the estimates optimum fishing mortality of Decapterus appears to be relatively low, comparing with calculated $F$ from subtraction $Z$ by $M$. The calculated total mortality value seem to be very high, although the approximation on natural mortality using empirical equation tends to result the same fashion. The values of $Z$ can be considered as over-estimate, due to very low numbers of older fish in the samples being caused by emigration.

In this case, precise exploitation level can not be inferred and attention should be taken in relation to the fraction of exploited stock inside the Java Sea and the amount of the adult fishes emigrating to other areas. In general, the concept of maximum sustainable yield applied exclusively to the Java Sea stock is not valid without including other fraction of the stock exploited by other fisheries beyond this area.

Under the condition that the biological data are strongly influenced by the migration activity, the biological analyses performed here tend to result pseudo estimates of parameters. The impact of emigration of the adult fishes (large size) to other region out side the Java Sea or beyond sampling area on length based estimation analysis makes the result become uncertain, or at least, it needs a particular attention in interpretation. We can show that the unsuccessful estimations on the mortality indices (instantaneous total and natural mortality) are due to the absence or the lack of the adult fishes in the samples. Mean while its impact on the growth estimate maynot be serious as that on mortality estimate, owing to the available facility in tracing the existing pseudo oscillation due to the above cause. Although the procedure used in the analysis maybe efficient in this estimation, but it is considerably bias.

\section{Bibliography}

Beverton, R. J. H. \& S. J. Holts. 1956. A review of methods for estimating mortality rates in fish populations, with special reference to sources of bias in catch sampling. Rapp. $-V$. Reun. CIEM 140. 67-83.

Beverton, R. J. H. \& S. J. Holts. 1957. On the dynamics of exploited fish populations. Fish. Invest., Ser. 2. 19. London.

Directorate General of Fisheries. 1995. Fisheries statistic 1994. DGF, Min. Agric. Jakarta.

Doubbleday, W. G., D. Rivard, \& W. D. McKone. 1984. Estimation of partial recruitment and yield per recruit for an otter trawl fishery for deepwater redfish. N. Am. J. Fish. Mgmt. 4, 1531.

Dwiponggo, A., T. Hariati, S. B. Atmaja, M. L. Palomares, \& D. Pauly. 1986. Growth, mortality, and recruitment of commercially important fishes and penaid shrimp in Indonesia waters. ICLARM Tech. Rep. 17. 91 p.

FAO-ICLARM. 1995. Stock assessment tools (FiSAT) user's guide. FAO. Rome.

Fréon, P. 1984. Des modèles de production appliquées des fractions de stocks dépendants des vents d'upwelling (pèche Sardinière au Senegal). Océanogr. Trop. 19. 67-94.

Gulland, J. A. 1983. Fish stock assessment: a manual of basic methods. FAO/J. Wiley \& Son. Ser. On Food and Agriculture. 223 p.

Gulland, J. A. \& Boerema. 1973. Scientific advice on catch levels. Fish. Bull. 71. 325-335. U.S.

Jones, R. 1974. Estimating population size from commercial statistics when fishing mortality varies with age. Conseil Permanent International pour l'Exploration de la Mer. Rapp. P_v. 155.

Jones, R. 1981. The use of length composition data in fish stock assessments (with notes on VPA and Cohort analysis). FAO Fish. Circ. 734. 54 p.

Jones, R. 1984. Assessing the effect of change in exploitation pattern using length composition 
data (with notes on VPA and cohort analysis). FAO Fish. Tech. Pap. 256.188 p.

Kizner, Z. I. \& D. A. Vasilyev. 1997. Instantaneous separable VPA (ISVPA). ICES J. Mar. Sci. 54, 399-411.

Luong, N. 1997. Java Sea Pelagic Fishery Assessment Project. AARD-ORSTOM. Sci.Tech.Doc.

Marcille, J. 1978. Dynamique de populations de crevettes exploitées à Madagascar. Travaux et Document de l'ORSTOM, 92. 1-165.

Mertz, G. \& R. A. Myers. 1996. An extended cohort analysis: Incorporating the effect of seasonal catches. Can. J. Fish. Aquat. Sci. 53. 159-163 p.

Pauly, D. 1990. Length converted catch curve and seasonal growth of fish. Fish Byte. 3 (8). Dec. 1990.

Pope J. G. \& J. G. Shepherd. 1985. A comparison of performance of various methods for tuning VPAs using effort data. J. CIEM. 42. 176-184.

Pope, J. G. 1972. An investigation of the accuracy of virtual population analysis using cohort analysis. Res. Bull. Int. Comm. Norwest Atl. Fish. 9. 65-74.

Pope, J. G. 1980. Phalanx analysis: An extension of Jones' length cohort analysis to multispecies cohort analysis. ICES, CM 1980/G: 19 (mimeo).

Potier, M. 1998. Pêcherie de layang et senneurs semi industriel javanaise: Perspective historique et approche système. Thèse de doctorat. Univ. Montpellier II. 300 p.
Potier, M. \& B. Sadhotomo. 1995. Trends in scad fishery of the Java Sea. The Fourth Asian Fisheries Forum. Beijing. October 1995.

Potier. M. \& B. Sadhotomo. 1995. Exploitation of the large and medium seiners fisheries. In $\mathrm{M}$. Potier \& S. Nurhakim (eds). Seminar on the Biology, Dynamics, and Exploitations. Java Sea Pelagic Fishery Assessment Project.

Sadhotomo, B. \& M. Potier. 1993a. Length composition of the main pelagic species caught by seiners of the Java Sea.1991-1992. Java Sea Pelagic Fishery Assessment Project. AARDORSTOM. Sci.Tech.Doc. 15.171 p.

Sadhotomo, B. \& M. Potier. 1993a. Length composition of the main pelagic species caught by seiners of the Java Sea:1993. Java Sea Pelagic Fishery Assessment Project. AARDORSTOM. Sci.Tech.Doc. 20. 90 p.

Sadhotomo, B. \& M Potier. 1995. Length composition of the main pelagic species caught by seiners of the Java Sea: 1994. Java Sea Pelagic Fishery Assessment Project. AARDORSTOM. Sci.Tech.Doc. 23. 124 p.

Sadhotomo, B. \& M. Potier. 1997. Length composition of the main pelagic species caught by seiners of the Java Sea: 1993. Java Sea Pelagic Fishery Assessment Project. AARDORSTOM. Sci.Tech.Doc. 27. 102 p.

Widodo, J. 1988. Population dynamics and management of ikan layang, scad mackerel, Decapterus spp. (Pisces: Carangidae) in the Java Sea. Ph.D thesis. University of Washington, Seattle. 150 p. 